\title{
The Role of Nitrogen Doping in the Performance of Carbon Nanotube Catalysts: A Catalytic Wet Peroxide Oxidation
} Application

\author{
Maria Martin-Martinez ${ }^{[a]}$, Rui S. Ribeiro ${ }^{[a]}$, Bruno F. Machado ${ }^{[b]}$, Philippe Serp ${ }^{[b]}$, Sergio Morales- \\ Torres $^{[c]}$, Adrián M.T. Silva ${ }^{[c]}$, José L. Figueiredo ${ }^{[c]}$, Joaquim L. Faria ${ }^{[c]}$, and Helder T. Gomes ${ }^{*[a]}$
}

\begin{abstract}
Four magnetic carbon nanotube samples (CNTs: undoped, completely $\mathrm{N}$-doped and two selectively $\mathrm{N}$-doped) have been synthesized by chemical vapor deposition. The materials were tested in the catalytic wet peroxide oxidation (CWPO) of highly concentrated 4-nitrophenol solutions (4-NP, $\left.5 \mathrm{~g} \mathrm{~L}^{-1}\right)$. Relatively mild operating conditions were considered (atmospheric pressure, $\mathrm{T}=50$ ${ }^{\circ} \mathrm{C}, \mathrm{pH}=3$ ), using a catalyst load of $2.5 \mathrm{~g} \mathrm{~L}^{-1}$ and the stoichiometric amount of $\mathrm{H}_{2} \mathrm{O}_{2}$ needed for the complete mineralization of 4-NP. $\mathrm{N}$-doping was identified to influence considerably the CWPO performance of the materials. In particular, undoped CNTs, with a moderate hydrophobicity, favor the controllable and efficient decomposition of $\mathrm{H}_{2} \mathrm{O}_{2}$ into highly reactive hydroxyl radicals ( $\mathrm{HO}$ ), thus showing high catalytic activity for 4-NP degradation. On the other hand, the completely $\mathrm{N}$-doped catalyst, fully hydrophilic, favors a quick decomposition of $\mathrm{H}_{2} \mathrm{O}_{2}$ into non-reactive $\mathrm{O}_{2}$ and $\mathrm{H}_{2} \mathrm{O}$ species The selectively $\mathrm{N}$-doped amphiphilic catalysts, i.e. hybrid structures containing undoped sections followed by $\mathrm{N}$-doped ones, provided intermediate results, namely: a higher $\mathrm{N}$ content favored $\mathrm{H}_{2} \mathrm{O}_{2}$ decomposition towards non-reactive $\mathrm{H}_{2} \mathrm{O}$ and $\mathrm{O}_{2}$ species, whilst a lower $\mathrm{N}$ content resulted in the formation of $\mathrm{HO}$; increasing 4-NP mineralization. Catalyst stability and reusability were also investigated by consecutive CWPO runs.
\end{abstract}

\section{Introduction}

During the past decade, the development and use of different nanostructured porous carbon materials in catalysis have

[a] Dr. M. Martín Martínez, R.S. Ribeiro, Dr. H.T. Gomes Laboratory of Separation and Reaction Engineering - Laboratory of Catalysis and Materials (LSRE-LCM)

Departamento de Tecnologia Química e Biológica, Escola Superior de Tecnologia e Gestão

Instituto Politécnico de Bragança

Campus de Santa Apolónia, 5300-253 Bragança, Portugal

E-mail: htgomes@ipb.pt

[b] Dr. B.F. Machado, Dr. P. Serp

Laboratoire de Chimie de Coordination UPR CNRS 8241,

composante ENSIACET

Université de Toulouse

UPS-INP-LCC 4 allé Emile Monso BP 44362, 31030 Toulouse Cedex 4, France

[c] Dr. S. Morales Torres, Dr. A.M.T. Silva, Dr. J.L. Figueiredo, Dr. J.L. Faria

Laboratory of Separation and Reaction Engineering - Laboratory of Catalysis and Materials (LSRE-LCM)

Departamento de Engenharia Química, Faculdade de Engenharia Universidade do Porto

Rua Dr. Roberto Frias s/n, 4200-465 Porto, Portugal

Supporting information for this article is given via a link at the end of the document increased in importance, being used as supports or as catalysts on their own [1]. Carbon nanotubes (CNTs) are particularly suitable for liquid-phase reactions, due to their high external surface area [2]. In addition, they exhibit high mechanical resistance, superior electronic properties, relatively high thermal stability under oxidizing conditions and tunable surface chemistry, making them highly versatile for several applications [2]. Moreover, the presence of nitrogen in the structure of CNTs increases their polarity and improves their reactivity towards different molecules [3]. In this sense, amphiphilic materials produced by selective $\mathrm{N}$-doping are gaining interest for several applications ${ }^{[4,5]}$. Pioneering works have reported the synthesis of magnetic amphiphilic N-doped CNTs from a $\mathrm{Fe} / \gamma-\mathrm{Al}_{2} \mathrm{O}_{3}$ catalyst and their successful application in different processes, such as adsorption of polyaromatic hydrocarbons ${ }^{[3]}$, chemical oxidation of alcohols ${ }^{[3,6]}$, and transesterification of soybean oil ${ }^{[3]}$. Moreover, it is known that the presence of $\mathrm{N}$-groups on the CNT surface highly enhances their activity for hydrogen peroxide $\left(\mathrm{H}_{2} \mathrm{O}_{2}\right)$ decomposition ${ }^{[7,8]}$.

Advanced oxidation processes (AOPs), primarily based on the action of hydroxyl radicals $\left(\mathrm{HO}^{*}\right)$ to oxidize organic pollutants, are regarded as promising solutions for the treatment of aqueous effluents from pharmaceutical, petrochemical, dye or paper industries, among others, containing recalcitrant and non-biodegradable compounds ${ }^{[9,10]}$ difficult to remove by conventional biological processes, mainly when present at high concentrations (1-10 $\left.\mathrm{g} \mathrm{L}^{-1}\right){ }^{[11]}$. Among them, catalytic wet peroxide oxidation (CWPO) uses $\mathrm{H}_{2} \mathrm{O}_{2}$ as source of $\mathrm{HO}^{\bullet}$ and a suitable catalyst for the degradation of the organic species under relatively mild conditions $\left(0.1-0.2 \mathrm{MPa} \text { and } 20-130{ }^{\circ} \mathrm{C}\right)^{[12,13]}$.

$\mathrm{H}_{2} \mathrm{O}_{2}$ easily decomposes into oxygen and water (eq. 1), releasing heat. Nevertheless, for the CWPO process, it is important to decompose selectively $\mathrm{H}_{2} \mathrm{O}_{2}$ into highly reactive $\mathrm{HO}$. The reaction mechanisms describing $\mathrm{H}_{2} \mathrm{O}_{2}$ decomposition are well accepted and reported in the literature, including the formation of $\mathrm{HO}$ with the participation of a suitable catalyst, as shown in eqs. 2 to 5 (where [AS] refers to an adequate active site at the surface of the catalyst, e.g. a surface reducing active site or a transition metal particle, among others) ${ }^{[14-20]}$. However, radical recombination may also occur (eqs. 6 to 8), affecting the efficiency of the CWPO process ${ }^{[15,21,22]}$.

$$
\begin{aligned}
& 2 \mathrm{H}_{2} \mathrm{O}_{2} \rightarrow 2 \mathrm{H}_{2} \mathrm{O}+\mathrm{O}_{2} \\
& \mathrm{H}_{2} \mathrm{O}_{2}+[\mathrm{AS}] \rightarrow\left[\mathrm{AS}^{\bullet+}\right]+\mathrm{OH}^{-}+\mathrm{HO}^{\bullet} \\
& \mathrm{H}_{2} \mathrm{O}_{2}+\left[\mathrm{AS}^{\bullet+}\right] \rightarrow[\mathrm{AS}]+\mathrm{H}^{+}+\mathrm{HOO}^{\bullet} \\
& \mathrm{H}_{2} \mathrm{O}_{2}+\mathrm{HO}^{\bullet} \rightarrow \mathrm{HOO}^{\bullet}+\mathrm{H}_{2} \mathrm{O} \\
& \mathrm{H}_{2} \mathrm{O}_{2}+\mathrm{HOO}^{\bullet} \rightarrow \mathrm{HO}^{\bullet}+\mathrm{H}_{2} \mathrm{O}+\mathrm{O}_{2} \\
& \mathrm{HO}^{\bullet}+\mathrm{HO}^{\bullet} \rightarrow \mathrm{H}_{2} \mathrm{O}_{2} \\
& \mathrm{HOO}^{\bullet}+\mathrm{HOO}^{\bullet} \rightarrow \mathrm{H}_{2} \mathrm{O}_{2}+\mathrm{O}_{2} \\
& \mathrm{HO}^{\bullet}+\mathrm{HOO}^{\bullet} \rightarrow \mathrm{H}_{2} \mathrm{O}+\mathrm{O}_{2}
\end{aligned}
$$

This article has been accepted for publication and undergone full peer review. Please cite this article as DOI: $10.1002 /$ cctc. 201600123 
The classical heterogeneous catalysts employed in CWPO consist of an active phase, mainly $\mathrm{Fe}$ or $\mathrm{Cu}$, immobilized on the surface of a porous support (activated carbon, silica, pillared clays or zeolites, among others). However, these catalysts usually suffer from severe deactivation due to leaching of the metallic phase after a few hours of operation [23-27]. Recently, metal-free carbon-based materials ${ }^{[28]}$ were found to be promising catalysts for CWPO, showing high activity and stability, and being able to ensure an efficient $\mathrm{H}_{2} \mathrm{O}_{2}$ usage, i.e. the selective formation of $\mathrm{HO}^{*}$ and further effective reaction with pollutant molecules ${ }^{[14,29-31]}$.

In previous studies [32,33], the behavior of different commercial CNTs in the CWPO process was analyzed. These materials were found to be highly effective for the removal of different phenolic compounds, even without added metal species. Since, to the best of our knowledge, amphiphilic CNTs have never been reported in CWPO, the present work aims to assess the role of N-doping in CNTs when employed in CWPO. In addition, the presence of reminiscent $\mathrm{Fe}$ in their structures, resulting from the synthesis procedure, will make them very attractive for CWPO applications coupled with in-situ magnetic separation systems for catalyst recovery. For this purpose, three different $\mathrm{N}$-doped CNTs (with varying doping levels) and one undoped CNT sample have been synthesized and characterized. A highly concentrated (5 $\mathrm{g} \mathrm{L} \mathrm{L}^{-1}$ ) 4-nitrophenol (4-NP) solution was considered as model system to simulate high-loaded wastewaters, challenging conditions normally not considered in CWPO studies ${ }^{[34-36]}$.

\section{Results and Discussion}

\section{Carbon nanotubes characterization}

The transmission electron microscopy (TEM) results reported in previous studies ${ }^{[3,6,37]}$, included in Table 1 , reveal that the introduction of nitrogen in the carbon structure induces an increase of the tube diameter and a decrease in the interstitial space between individual CNTs. Undoped E30 consists of very regular multi-walled CNTs with an average external diameter of ca. $8 \mathrm{~nm}$ and Fe particles encapsulated in the structure (formed during the catalytic chemical vapor deposition (CVD) synthesis by reduction of the iron oxide using $\mathrm{H}_{2}$ produced during the decomposition of the carbon sources at high temperature, and that remained in the CNT structure after the purification step with $\mathrm{H}_{2} \mathrm{SO}_{4}$ (see Experimental Section)). The yield of the CVD process was $4.8 \mathrm{gc} \mathrm{g}_{\mathrm{cat}}{ }^{-1}{ }^{[3]}$. On the other hand, the completely $\mathrm{N}$-doped $\mathrm{A} 30$, generated in a considerable lower yield $\left(1.1 \mathrm{gc} \mathrm{g}_{\mathrm{cat}}{ }^{-1}\right)^{[3]}$, is characterized by a "bamboo-like" structure with larger diameters (ca.14 nm). The selectively N-doped materials are hybrid structures containing both undoped and $\mathrm{N}$ doped sections with intermediate diameters (Figure S1). Analysis of the $\mathrm{N}_{2}$ adsorption-desorption isotherms obtained with the different CNTs (Figure S2; Table 1) reveals the highest value of specific surface area $\left(\mathrm{S}_{\mathrm{BET}}\right)$ for the undoped material $(\mathrm{E} 30)$ consistent with the lower tube diameter and hollow nature of its structure. It should be noted the area available inside E30 (assuming some opened tubes), contrary to the doped CNTs where the bamboo-type structure prevents a significant adsorption inside the tubes. With regard to the $\mathrm{N}$-doped nanotubes, despite their larger tube diameter, the $\mathrm{S}_{\mathrm{BET}}$ of the completely $\mathrm{N}$-doped material (A30) is similar to that obtained for the selectively N-doped CNTs (E10A20 and E3A27), which might be explained by the smaller interstitial space shown by A30. The mesopore and total pore volumes also decrease as the nitrogen content in the CNT increases, which could be explained by a more efficient packing of the CNTs due to excess hydrogen bonding between functional groups, leading to thicker bundles ${ }^{[38,39]}$. In all cases, the nitrogen uptake dramatically increased at high relative pressures leading to a soft hysteresis loop, which may be associated to capillary condensation in the mesoporous structure of the CNT bundles ${ }^{[40,41]}$. By comparing the obtained isotherms, a significant difference in the shape of the hysteresis loop and a shift towards lower relative pressures are recorded for the completely $\mathrm{N}$-doped $\mathrm{A} 30$ material, indicating a less uniform pore size distribution in this sample when compared to the other CNTs.

Table 1. Textural properties (average tube diameter and interstitial spacing, in $\mathrm{nm}$ ) of the CNTs, extracted from TEM micrographs and $\mathrm{N}_{2}$ adsorption-desorption isotherms.

\begin{tabular}{llllll}
\hline Catalyst & $\begin{array}{l}\text { Tube } \\
\text { diameter } \\
(\mathrm{nm})^{[\mathrm{a}]}\end{array}$ & $\begin{array}{l}\text { Interstitial } \\
\text { space } \\
(\mathrm{nm})^{[\mathrm{a}]}\end{array}$ & $\begin{array}{l}\mathrm{S}_{\mathrm{BET}} \\
\left( \pm 5 \mathrm{~m}^{2} \mathrm{~g}^{-1}\right)\end{array}$ & $\begin{array}{l}\mathrm{V}_{\text {pore }} \\
( \pm 0.01 \\
\left.\mathrm{cm}^{3} \mathrm{~g}^{-1}\right)\end{array}$ & $\begin{array}{l}\mathrm{V}_{\text {meso }} \\
( \pm 0.01 \\
\left.\mathrm{cm}^{3} \mathrm{~g}^{-1}\right)\end{array}$ \\
\hline E30 & 8 & 30.0 & 275 & 1.92 & 1.72 \\
E10A20 & 9 & 21.9 & 214 & 1.49 & 1.26 \\
E3A27 & $n / a$ & $n / a$ & 196 & 1.31 & 1.22 \\
$\mathrm{A30}$ & 14 & 14.8 & 212 & 1.11 & 0.74 \\
\hline
\end{tabular}

[a] data from ${ }^{[6]}$. n/a: not available.

The N-doped CNT structure is known to show several defects and the presence of nitrogen in the graphitic network induces a curvature of the tube graphitic layers ${ }^{[42]}$. X-ray diffraction (XRD), thermogravimetric and Raman analysis carried out previously $[3,6,37]$ support the well-organized carbon structure of E30, as opposed to the more defective and reactive carbon present in A30, since a significant increase of defects occurs when increasing the $\mathrm{N}$ content. Briefly, Raman spectra showed the presence of one first order peak at ca. $1560 \mathrm{~cm}^{-1}$ (G-band) and three second order features at ca. $1330 \mathrm{~cm}^{-1}$ (D- band), ca. 2700 $\mathrm{cm}^{-1}$ (G-band) and ca. $2940 \mathrm{~cm}^{-1}$ (combined D/G-bands). The higher the ratio between $D$ and $G$ band intensities $\left(I_{D} / I_{G}\right)$, the more defective is the structure under study. This parameter decreases from 0.8 in A30 to 0.6 in E30. At the same time, XRD analysis showed a slight decrease of the $d_{002}$ distance with the nitrogen content, from $3.43 \AA$ in $\mathrm{E} 30$ to $3.36 \AA$ in $\mathrm{A} 30$.

X-ray photoelectron spectroscopy (XPS) results (Table 2) confirm the low amount of nitrogen-containing surface groups on the $\mathrm{N}$-doped materials, since these are mainly building blocks for the internal $\mathrm{N}-\mathrm{C}$ bonds. Nevertheless, as reported before ${ }^{[3]}$, the 
deconvolution of the $\mathrm{N}$ 1s region of the XPS spectra (Figure S3) shows the presence of pyridinic nitrogen (N6), pyrrolic nitrogen (N5), quaternary nitrogen (NQ) and nitrogen oxides (N-oxides) in the $\mathrm{N}$-doped materials, strongly affecting the CNT reactivity due to their electron-donating properties. Pyridinic nitrogen, present on the edge of graphite planes bonded to two carbon atoms, has a well-known basic character, slightly higher than that shown by the pyrrolic nitrogen. Both structures contain a basic nitrogen atom with a lone pair of electrons to donate. On the other hand, the positive charge of the quaternary nitrogen, in which nitrogen is within a graphite plane and bonded to three carbon atoms, favors the electron transfer reactions in the CNT surface. The peak related to nitrogen oxides is also present in the $01 \mathrm{~s}$ region of the $\mathrm{N}$-doped materials (Table 2; Figure S4). The 01s deconvolution reveals the presence of oxygen-containing surface groups in the CNTs as well, which could be formed during the CNT purification step with $\mathrm{H}_{2} \mathrm{SO}_{4}$. Although present in small amounts, the electron withdrawing properties of these surface acidic oxygen-containing groups may also affect the reactivity of the CNTs. As observed in Table 2, the amount of oxygen-containing surface groups increases with the $\mathrm{N}$ content, affecting the type of surface chemical functionalities. While the undoped and the selectively N-doped CNTs (E30 and E10A20) present intermediate amounts of carbonyl/carboxylic acid groups $(\mathrm{C}=\mathrm{O})$ and phenol/ether groups $(\mathrm{C}-\mathrm{O})$, the materials with high $\mathrm{N}$ content (E3A27 and A30) present carbonyl/carboxylic acid groups in their surface. This is in accordance with the potentiometric titration curves (Figure S5), since the completely $\mathrm{N}$-doped sample exhibits a broadening of the buffering area, showing the highest amount of surface acidic groups (Table 3). On the other hand, in spite of its small concentration, the total Fe on the CNTs also seems to increase with the presence of $\mathrm{N}$ (Table 2), in accordance with the remaining bulk Fe content determined in a previous study, which decrease from ca. $5 \%$ in the $\mathrm{N}$-doped $\mathrm{A} 30$ to ca. $2 \%$ in the undoped E30 ${ }^{[6]}$.

Table 2. Surface atomic composition (in \%, by XPS) of the CNTs

\begin{tabular}{llllllllllllll}
\hline Catalyst & $\mathrm{C}$ & $\mathrm{O}$ & $\mathrm{N}$ & $\mathrm{Fe}$ & \multicolumn{3}{c}{$\mathrm{N}_{1 \mathrm{~s}}(\%)$} & & \multicolumn{3}{c}{$\mathrm{O}_{1 \mathrm{~s}}(\%)$} \\
& $(\%)$ & $(\%)$ & $(\%)$ & $(\%)$ & $\mathrm{N} 6$ & $\mathrm{~N} 5$ & $\mathrm{NQ}$ & $\mathrm{N}-\mathrm{ox}$ & $\mathrm{C}=0$ & $\mathrm{C}-\mathrm{O}$ & $\mathrm{N}-\mathrm{ox}$ \\
\hline E30 & 99.0 & 0.85 & - & 0.05 & - & - & - & - & 46 & 54 & - \\
E10A20 & 98.9 & 0.75 & 0.29 & 0.06 & 37 & 17 & 26 & 20 & 46 & 51 & 3 \\
E3A27 & 94.9 & 1.6 & 3.4 & 0.2 & 33 & 6 & 27 & 34 & 58 & 29 & 13 \\
A30 & 91.8 & 2.7 & 5.3 & 0.3 & 31 & 7 & 28 & 34 & 64 & 29 & 7 \\
\hline
\end{tabular}

As explained above, both the undoped E30 and the completely $\mathrm{N}$-doped A30 materials contain a single structure, consisting of very regular multi-walled CNTs in E30 and "bamboo-like" CNTs A30. The thermogravimetric (TGA) curve (Figure 1) of the undoped E30 sample shows a maximum weight loss at $562.5^{\circ} \mathrm{C}$, which corresponds to the typical combustion temperature of multi-walled CNTs [43]. On the other hand, the completely $\mathrm{N}$-doped A30 sample presented its maximum loss at a lower temperature $\left(539.2^{\circ} \mathrm{C}\right)$, coherent with a more defective structure and the presence of oxygen- and nitrogen-containing surface groups. As pointed out by the TEM results, the TGA curves of the selectively $\mathrm{N}$-doped CNTs confirm the presence of both structures in these materials, since two negative peaks situated at around 500 and $600{ }^{\circ} \mathrm{C}$ may be clearly identified when representing the weight loss derivative (DTG curve), corresponding to $\mathrm{N}$-doped and undoped sections, respectively.

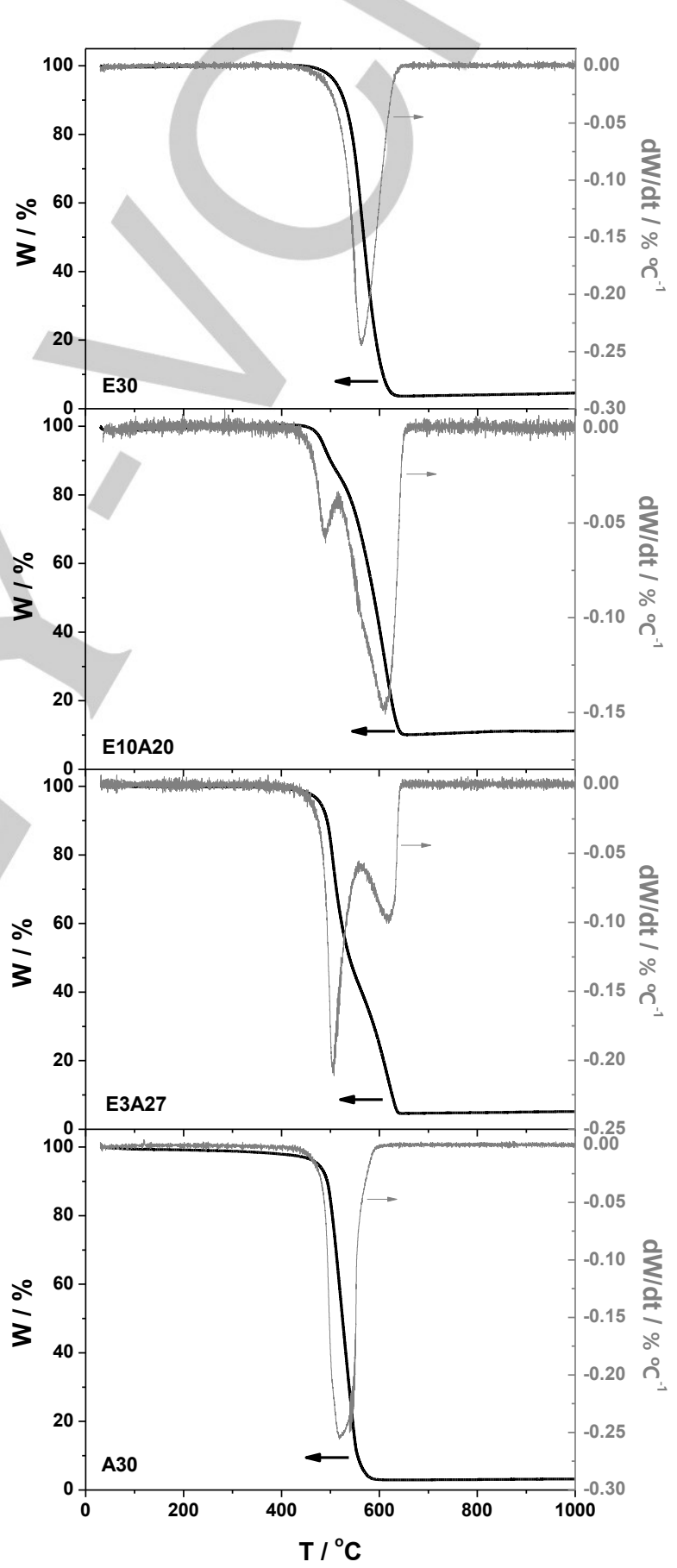

Figure 1. Weight loss by TGA of the CNTs (black) and its derivative (grey). 
Finally, the water contact angle measurements obtained for the buckypapers composed of different CNTs (Table 3 ) seem to be correlated with the amount of oxygen- and nitrogen-containing functional groups incorporated during the CNT synthesis. In this context, the undoped material $\mathrm{E} 30$ has a moderate hydrophobicity (contact angle of $60^{\circ}$ ), while the $\mathrm{N}$-doped catalysts are highly hydrophilic, in particular the completely $\mathrm{N}$ doped A30 (contact angle of $11^{\circ}$ ). The hydrophilic properties and the $\mathrm{N}$-doping were found to strongly influence the activity and effectiveness of the CNTs when used as catalysts in the CWPO of 4-NP, as shown in the next section.

Table 3. Concentration of surface acidic groups $\left(\mathrm{mmol} \mathrm{g}^{-1}\right)$ and contact angles $\left({ }^{\circ}\right)$ determined for buckypapers prepared with different CNTs.

\begin{tabular}{lllll}
\hline Catalyst & $\mathrm{E} 30$ & $\mathrm{E} 10 \mathrm{~A} 20$ & $\mathrm{E3A27}$ & $\mathrm{A} 30$ \\
\hline $\begin{array}{l}\text { Acidic groups } \\
(\mathrm{mmol} \mathrm{g})^{-1}\end{array}$ & 0.146 & 0.162 & n.d. & 0.337 \\
$\begin{array}{l}\text { Contact } \\
\text { angle } \\
\left({ }^{\circ}\right)\end{array}$ & & & & \\
\hline
\end{tabular}

n.d.: not determined

\section{Catalytic activity}

Screening experiments were performed in order to evaluate the performance of the synthesized CNTs during the CWPO of 4-NP The conversions $(X)$ of 4-NP, total organic carbon (TOC) and $\mathrm{H}_{2} \mathrm{O}_{2}$ achieved with each catalyst, as well as the concentration of $\mathrm{Fe}$ leached into the solution, after $24 \mathrm{~h}$ of reaction, are given in Figure 2. The removal of 4-NP in the absence of $\mathrm{H}_{2} \mathrm{O}_{2}$ is also shown in order to differentiate between pure adsorption and CWPO.

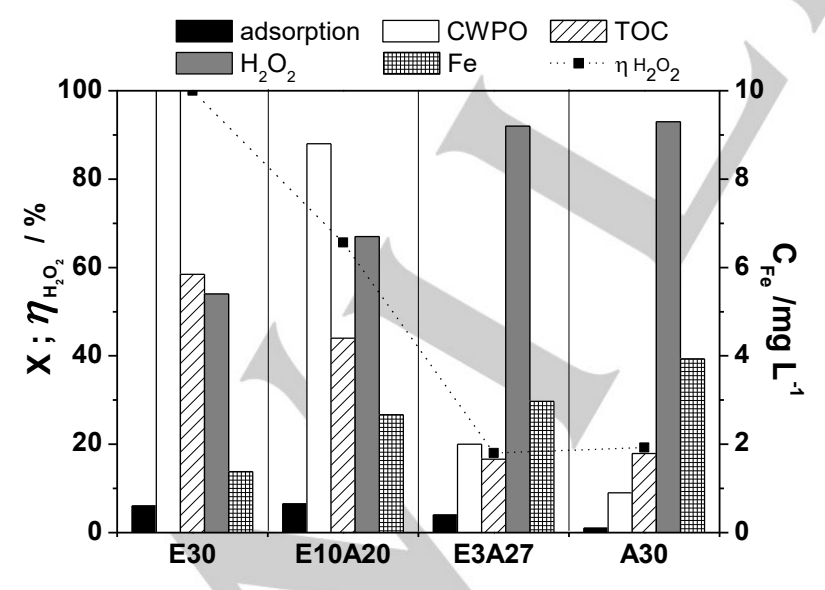

Figure 2. Removal of 4-NP from aqueous solution by adsorption and by CWPO; TOC removal, $\mathrm{H}_{2} \mathrm{O}_{2}$ decomposition, Fe leaching (right $\mathrm{y}$-axis) and $\eta_{\mathrm{H}_{2} \mathrm{O}_{2}}$ obtained in the CWPO experiments; results after $24 \mathrm{~h}$.
As observed, the contribution of adsorption is negligible in all cases and decreases with increasing $\mathrm{N}$ content, presumably due to a weaker interaction with the $\mathrm{N}$-doped surface. This enables the direct comparison of the different CNTs as catalysts in the CWPO experiments. All catalysts remarkably decompose $\mathrm{H}_{2} \mathrm{O}_{2}$, but with rather different catalytic activity. As expected, $\mathrm{H}_{2} \mathrm{O}_{2}$ consumption increases in the CNTs with higher amount of nitrogen ${ }^{[7,8]}$, since the presence of electron donating groups on these materials favor the decomposition of $\mathrm{H}_{2} \mathrm{O}_{2}$. However, contrary to expectations, 4-NP removal decreases with increasing $\mathrm{H}_{2} \mathrm{O}_{2}$ consumption; $100 \%$ of the pollutant was removed after $24 \mathrm{~h}$ with the undoped material (E30), while only a $9 \%$ removal was observed with the completely $\mathrm{N}$-doped sample (A30). This singular behavior may be explained by the different physicochemical properties of the synthesized CNTs. In a previous study, it has been reported the ability of several carbon materials with different structural and chemical properties to selectively decompose $\mathrm{H}_{2} \mathrm{O}_{2}$ into $\mathrm{HO}$ radicals, revealing that the presence of basic groups in the carbon materials increases the yield of $\mathrm{HO}^{\circ}$ formation ${ }^{[14]}$. On the other hand, the hydrophilic $\mathrm{N}$ doped catalysts have a strong affinity towards polar molecules like $\mathrm{H}_{2} \mathrm{O}_{2}$. The insertion of $\mathrm{N}$ atoms in the CNT structure lowers the electron work function value of the carbonaceous surface decreasing the band gap, thus producing a higher electron mobility and enhancing the decomposition of $\mathrm{H}_{2} \mathrm{O}_{2}{ }^{[44]}$ into $\mathrm{HO}$ radicals, which ultimately result in the formation of non-reactive $\mathrm{O}_{2}$ and $\mathrm{H}_{2} \mathrm{O}$ species during the CWPO experiments. As explained in the Introduction, the formation of non-reactive species occurs in a two-step mechanism: first, $\mathrm{H}_{2} \mathrm{O}_{2}$ decomposes into reactive radicals, and second these radicals react between them, recombining into non-reactive species. Therefore, with the exception of E10A20, very low 4-NP removal is reached by CWPO with the N-doped catalysts. On the other hand, the undoped E30 sample, which is moderately hydrophobic, has a modest affinity towards $\mathrm{H}_{2} \mathrm{O}_{2}$, resulting in a controllable and more efficient $\mathrm{H}_{2} \mathrm{O}_{2}$ decomposition into $\mathrm{HO}^{\circ}$, the first step in the CWPO process. These radicals further react with 4-NP adsorbed in the close vicinity of the active sites, resulting in a remarkable removal of 4-NP.

The different affinity of the CNTs for the reactant molecules $\left(\mathrm{H}_{2} \mathrm{O}_{2}\right.$ and 4-NP) also affects the mineralization level obtained, the TOC conversion decreasing when using the CNTs with higher amount of nitrogen. Due to a more efficient $\mathrm{H}_{2} \mathrm{O}_{2}$ decomposition into $\mathrm{HO}^{*}$, the undoped $\mathrm{E} 30$ catalyst converts ca. $60 \%$ of the TOC content after $24 \mathrm{~h}$. On the other hand, the inefficient decomposition of $\mathrm{H}_{2} \mathrm{O}_{2}$ into non-reactive species with the completely $\mathrm{N}$-doped $\mathrm{A} 30$ hinders the reaction (TOC conversion of only ca. $18 \%$ ). This higher efficiency in the $\mathrm{H}_{2} \mathrm{O}_{2}$ decomposition with $\mathrm{E} 30$ is highlighted when analyzing the TOC removal per unit of $\mathrm{H}_{2} \mathrm{O}_{2}$ decomposed $\left(\eta_{\mathrm{H}_{2} \mathrm{O}_{2}}\right)$. In this case, an efficiency of ca. $100 \%$ is observed, suggesting that all the decomposed $\mathrm{H}_{2} \mathrm{O}_{2}$ is effectively used in the mineralization of 4-NP. In contrast, only ca. $20 \%$ of the decomposed $\mathrm{H}_{2} \mathrm{O}_{2}$ was used in the mineralization of the pollutant with the highly $\mathrm{N}$-doped E3A27 material and the completely $\mathrm{N}$-doped A30 sample. 
Both the increase of structural defects in carbon materials $[45,46]$ and presence of $\mathrm{Fe}$ at their surface ${ }^{[33,47]}$ have been shown to increase the efficiency of CWPO processes, mainly related to increased $\mathrm{H}_{2} \mathrm{O}_{2}$ consumption. Nevertheless, when the sequence of the 4-NP removal obtained by CWPO in the presence of each catalyst $(\mathrm{E} 30>\mathrm{E} 10 \mathrm{~A} 20>\mathrm{E} 3 \mathrm{~A} 27>\mathrm{A} 30)$ is directly compared to that of the amount of surface $\mathrm{Fe}$ and defects in the structure of the catalysts $(\mathrm{A} 30>\mathrm{E} 3 \mathrm{~A} 27>\mathrm{E} 10 \mathrm{~A} 20>\mathrm{E} 30)$ an opposite tendency is observed. Therefore, surface $\mathrm{Fe}$ and structural defects cannot explain the results shown in Figure 2, suggesting that $\mathrm{N}$-doping is a determining factor influencing the CNTs activity. The different textural properties observed for the CNTs could also have some influence on the catalyst activity. In particular, E30 is the most active material, with the highest $\mathrm{S}_{\mathrm{BET}}$, mesopore $\left(\mathrm{V}_{\text {meso }}\right)$, and total pore $\left(\mathrm{V}_{\text {pore }}\right)$ volumes, which could favor the accessibility of $\mathrm{H}_{2} \mathrm{O}_{2}$ to the active sites as well as 4-NP adsorption. However, these values are, in general, similar for all the samples, the differences being only significant for E30. Therefore, it is possible to conclude that the influence of the $\mathrm{N}$ doping surpasses that of the textural properties of the CNTs.

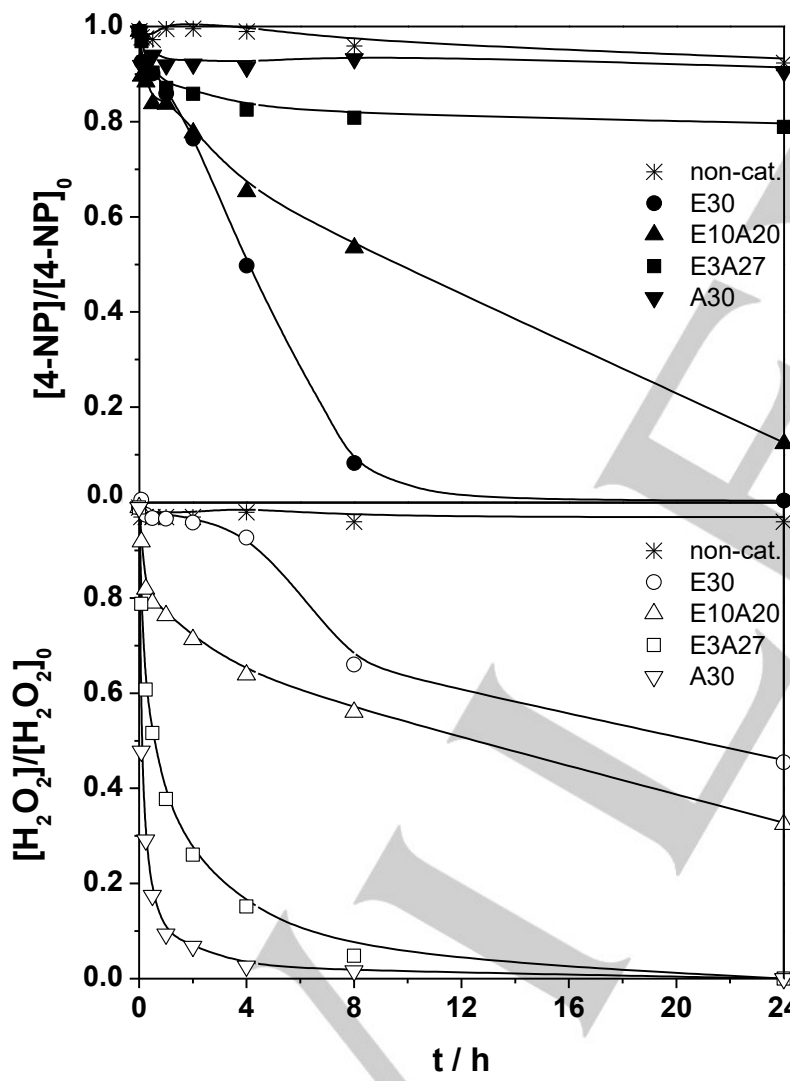

Figure 3. Concentration evolution with time (h) for 4-NP (top, solid symbols) and $\mathrm{H}_{2} \mathrm{O}_{2}$ (bottom, open symbols) during the CWPO experiments (normalized by the corresponding initial concentrations).

In addition, the higher Fe leaching observed with the N-doped catalysts is in agreement with the higher content of $\mathrm{Fe}$ on the surface of the $\mathrm{N}$-doped catalysts, and to the favorable conditions found at their surface for fast and inefficient $\mathrm{H}_{2} \mathrm{O}_{2}$ decomposition, resulting in the oxidation of the $\mathrm{Fe}$ particles and consequent leaching into the solution. Despite the higher amounts of leached $\mathrm{Fe}$ in the reactions with the $\mathrm{N}$-doped catalysts, this factor does not lead to an increased 4-NP removal, discarding the homogeneous contribution promoted by $\mathrm{Fe}$ species in the solution. This further emphasizes the influence of $\mathrm{N}$-doping on the efficiency of the CWPO process, as explained previously, by the different surface interactions between CNTs, $\mathrm{H}_{2} \mathrm{O}_{2}$ and 4-NP.

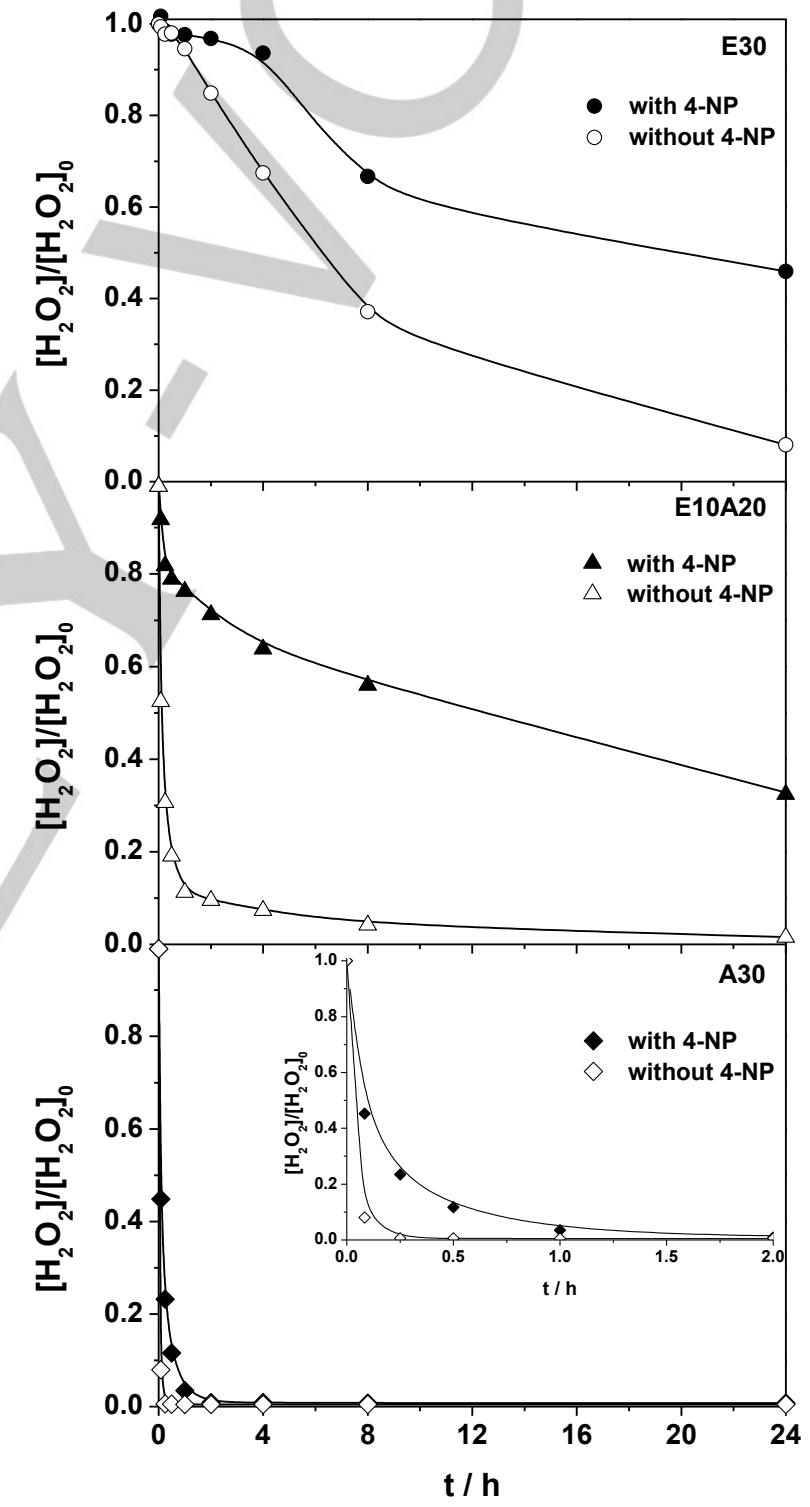

Figure 4. Concentration evolution with time (h) for $\mathrm{H}_{2} \mathrm{O}_{2}$ in experiments with (solid symbols) and without (open symbols) pollutant, using E30, E10A20 and A30.

As explained above, the presence of electron donating groups substantially favors the decomposition of $\mathrm{H}_{2} \mathrm{O}_{2}$. By studying the 
time-evolution of 4-NP and $\mathrm{H}_{2} \mathrm{O}_{2}$ concentrations obtained with each catalyst during the CWPO runs (Figure 3 ), it can be observed that, while E30 and E10A20 decompose $\mathrm{H}_{2} \mathrm{O}_{2}$ at a moderate rate, the highly and completely $\mathrm{N}$-doped materials (E3A27 and A30, respectively) promote a sharp decomposition of this oxidizing agent (also visually observed by the intense formation of gas bubbles and white smog in the reactor, pointing to the formation of $\mathrm{O}_{2}$ and $\mathrm{H}_{2} \mathrm{O}$ due to recombination of the radicals)

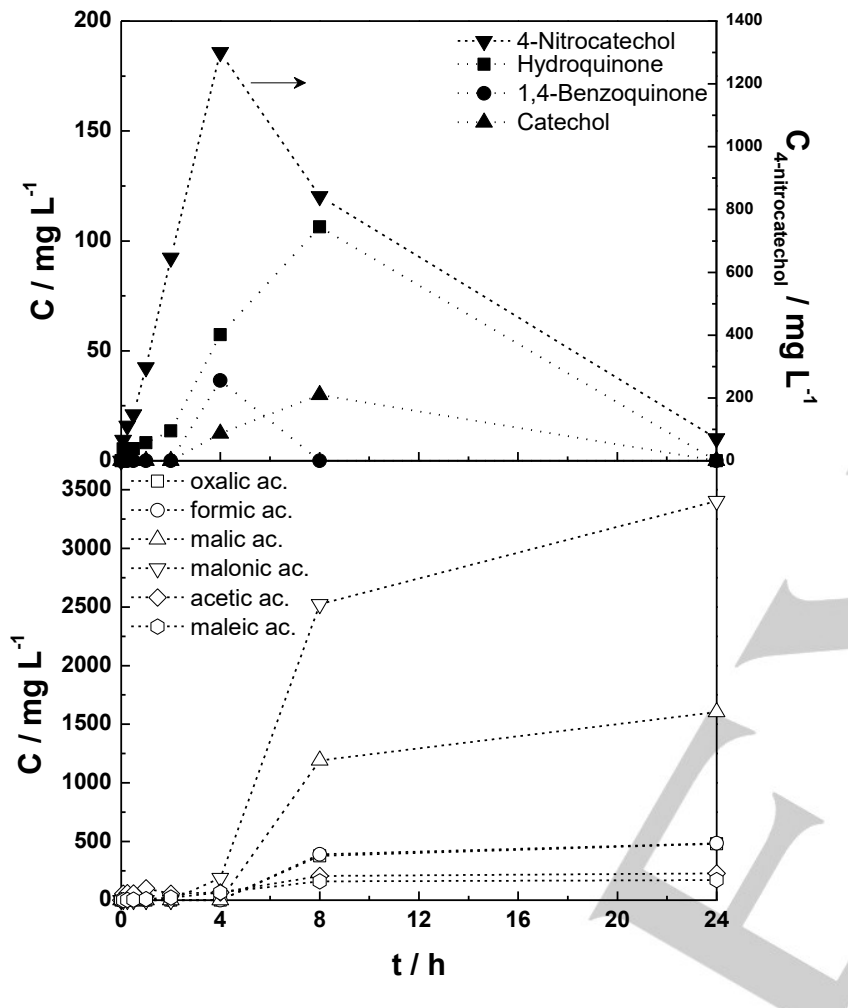

Figure 5. Concentration ( $\mathrm{mg} \mathrm{L}^{-1}$ ) evolution with time $(\mathrm{h})$ for the different compounds resulting from the CWPO of 4-NP using E30.

In order to understand better the different behavior of the catalysts, the decomposition of $\mathrm{H}_{2} \mathrm{O}_{2}$ was studied without the presence of the pollutant. Figure 4 shows $\mathrm{H}_{2} \mathrm{O}_{2}$ concentration as a function of time in the experiments carried out with and without 4-NP with three representative catalysts: the undoped E30 catalyst, the selectively $\mathrm{N}$-doped $\mathrm{E} 10 \mathrm{~A} 20$ and the completely $\mathrm{N}$ doped $A 30$. It is observed that the decomposition of $\mathrm{H}_{2} \mathrm{O}_{2}$ in the absence of 4-NP is faster in all cases, which may be explained by the absence of adsorption competition between $\mathrm{H}_{2} \mathrm{O}_{2}$ and 4NP molecules on the surface of the catalyst. It is noteworthy the large difference found in the catalyst E10A20 with and without 4$\mathrm{NP}$, revealing that the competition between $\mathrm{H}_{2} \mathrm{O}_{2}$ and 4-NP for the catalyst surface hindered the strong affinity of $\mathrm{H}_{2} \mathrm{O}_{2}$ for the CNTs, resulting in a gradual decomposition of this reactant during the CWPO of 4-NP.

\section{Reaction mechanism}

In order to correlate the CWPO reaction mechanism with the different physicochemical properties of the synthesized CNTs, a more detailed study was carried out with the three representative catalysts: $E 30, E 10 A 20$, and $A 30$. As observed in Figure 2, complete TOC conversion was never achieved with any of the catalysts, suggesting the existence of organic intermediates and/or by-products at the end of the reaction. Accordingly, Figures 5-7 show the time-evolution of the different compounds that were identified during the CWPO of 4-NP with $\mathrm{E} 30, \mathrm{E} 10 \mathrm{~A} 20$, and $\mathrm{A} 30$, respectively. As expected, the evolution of the identified compounds is quite different with each catalyst.

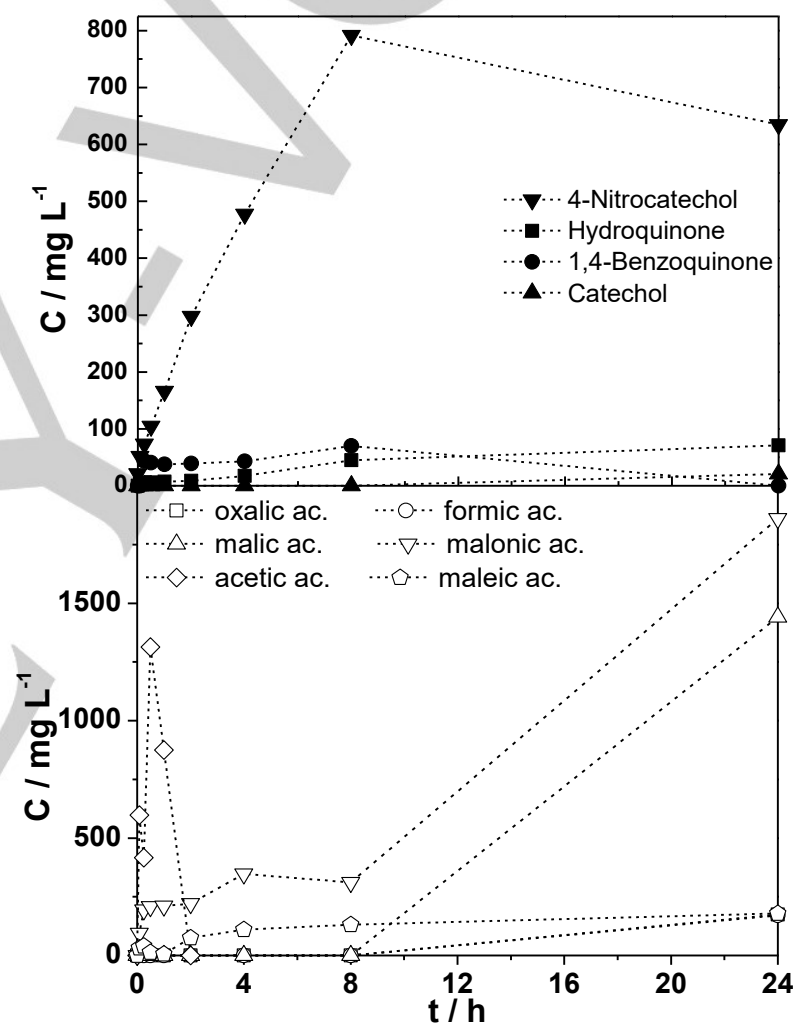

Figure 6. Concentration $\left(\mathrm{mg} \mathrm{L}^{-1}\right)$ evolution with time $(\mathrm{h})$ for the different compounds resulting from the CWPO of 4-NP using E10A20.

The first difference is related with the total concentration of intermediates and/or by-products obtained. The fast $\mathrm{H}_{2} \mathrm{O}_{2}$ consumption compared to 4-NP adsorption/decomposition, when using A30 limits the CWPO process. Therefore, small amounts of these compounds were detected with A30. Specifically, intermediate compounds were mainly formed during the first $2 \mathrm{~h}$ of reaction, while $\mathrm{H}_{2} \mathrm{O}_{2}$ was still present in the solution. As described in a previous study ${ }^{[45]}$, the electrophilic addition of $\mathrm{HO}^{\bullet}$ to the aromatic ring of 4-NP favors the formation of 4-nitrocatechol, which was by far the main aromatic compound formed with all the catalysts. However, secondary reactions also occur: (i) the denitration of the 4-NP molecule 
leading to the formation of hydroquinone, which may be further oxidized to 1,4-benzoquinone [45,48]; (ii) the electrophilic $\mathrm{HO}^{\circ}$ addition at the ortho position leading to the formation of catechol. This is consistent with the aromatic intermediates observed with the undoped E30 catalyst (Figure 5). In this case, the concentrations observed follow the sequence: 4-nitrocatechol >> hydroquinone $>1$,4-benzoquinone $\approx$ catechol. On the other hand, with the completely $\mathrm{N}$-doped $\mathrm{A} 30$ catalyst (Figure 7), the reaction medium was remarkably oxidizing due to the strong affinity between the catalysts and $\mathrm{H}_{2} \mathrm{O}_{2}, 1$,4-benzoquinone being rapidly obtained. After about $2 \mathrm{~h}$ of reaction, $\mathrm{H}_{2} \mathrm{O}_{2}$ was completely consumed and 1,4-benzoquinone was immediately reduced back to hydroquinone, showing an atypical behavior in CWPO reactions.

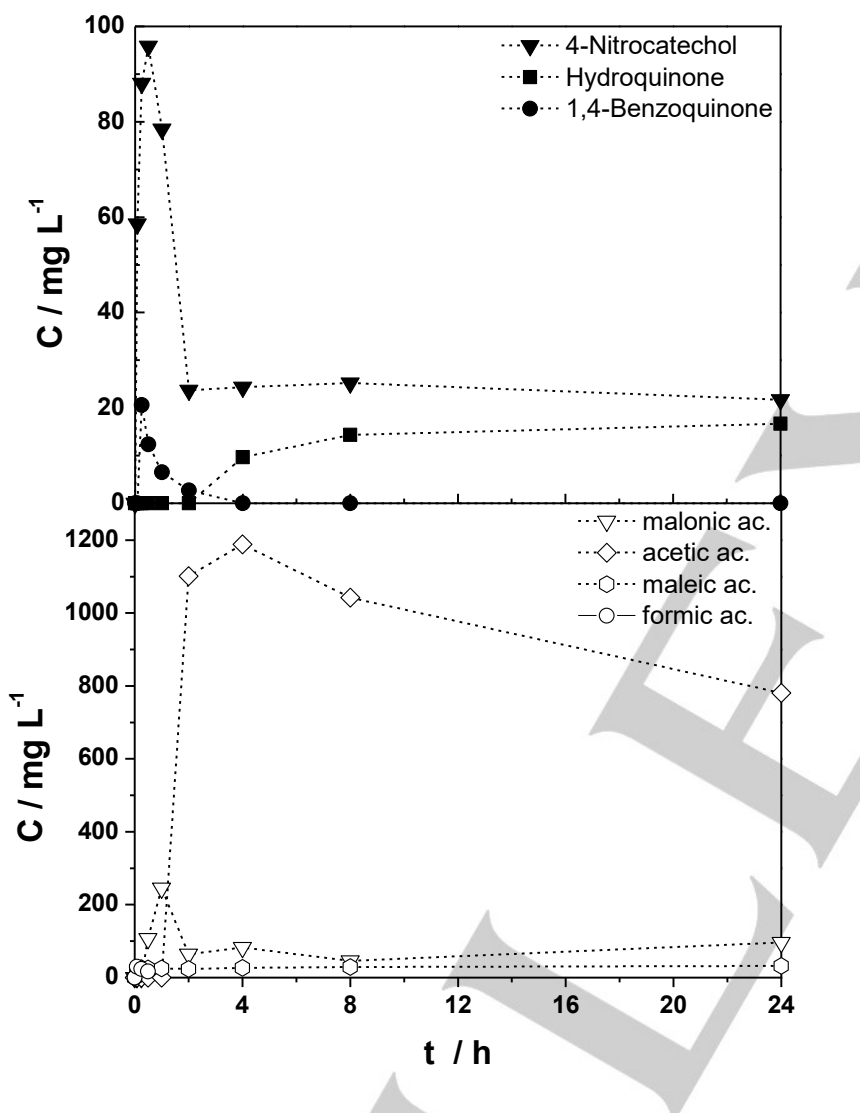

Figure 7. Concentration ( $\left.\mathrm{mg} \mathrm{L}^{-1}\right)$ evolution with time (h) for the different compounds resulting from the CWPO of 4-NP using A30.

As reported in previous studies ${ }^{[32,45]}, \mathrm{HO} \cdot$ radicals further attack these aromatic intermediates leading to the ring opening, and yielding low molecular weight carboxylic acids. With the undoped E30 catalyst (Figure 5), the aromatic intermediates were almost completely converted after $24 \mathrm{~h}$ of reaction and high concentrations of carboxylic acids were obtained, causing a dramatic decrease in the solution $\mathrm{pH}$ at the end of the reaction (dropping from 3 to 1.8). With the $\mathrm{N}$-doped $\mathrm{A} 30$ sample (Figure 7), as explained above, the reaction environment in the first hours of reaction helped to highly oxidize 4-NP, forming considerable amounts of acetic acid, which decreased again when the reaction medium switch to a non-oxidizing environment. The E10A20 catalyst behaved like A30 during the first minutes of reaction (Figure 6), with large amounts of acetic acid being formed. However, after that, due to the competition between $\mathrm{H}_{2} \mathrm{O}_{2}$ and 4-NP adsorption on the catalyst surface, the remaining $\mathrm{H}_{2} \mathrm{O}_{2}$ decomposed gradually and efficiently into $\mathrm{HO}^{*}$, switching to the undoped material-like behavior.

All the findings reported so far contribute to understand further the 4-NP CWPO mechanism when applying catalysts with different properties, as represented in Figure 8 . The hydrophilic $\mathrm{N}$-doped surfaces strongly attract the $\mathrm{H}_{2} \mathrm{O}_{2}$ molecules, which are quickly decomposed into radicals on the active sites with $\mathrm{N}$-containing functionalities, due to their electron donating properties. The organic pollutant molecules cannot compete with $\mathrm{H}_{2} \mathrm{O}_{2}$ for the catalyst surface. Consequently, in a second stage, the radicals formed in large amounts do not react with the pollutant, but between themselves, recombining into nonreactive $\mathrm{O}_{2}$ and $\mathrm{H}_{2} \mathrm{O}$. The more hydrophobic undoped surfaces attract both $\mathrm{H}_{2} \mathrm{O}_{2}$ and pollutant molecules. $\mathrm{H}_{2} \mathrm{O}_{2}$ is decomposed into radicals, which immediately attack the pollutant molecules adsorbed in the close vicinity, leading to their efficient mineralization. The hydrophilic $\mathrm{N}$-doped sections in the hybrid structure strongly attract the $\mathrm{H}_{2} \mathrm{O}_{2}$ molecules. However, in this case, the pollutant molecule can approach the undoped sections and reach the catalyst surface, reacting with the formed radicals. This mechanistic insight puts into evidence amphiphilic materials as promising catalysts for CWPO.

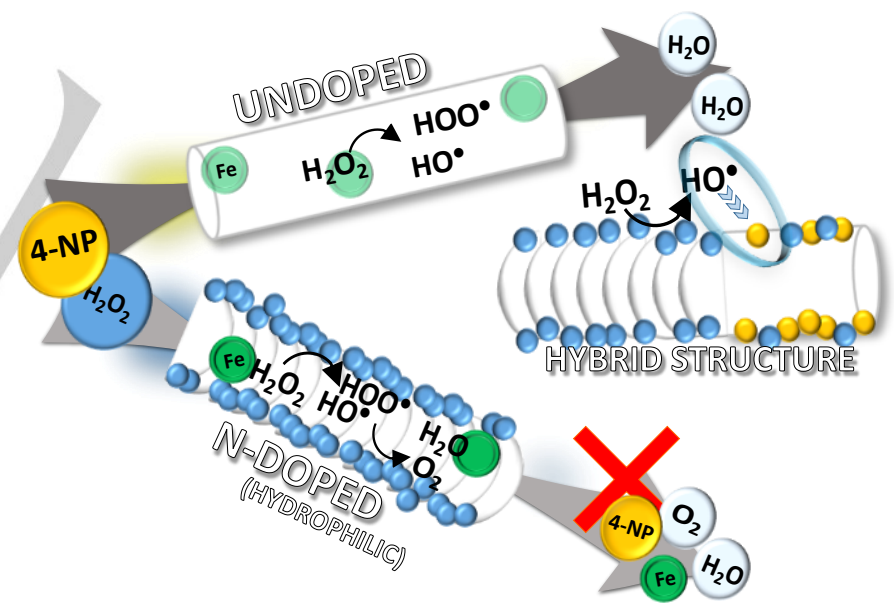

Figure 8. Representation of the proposed mechanism for the CWPO of 4-NP in $\mathrm{N}$-doped hydrophilic and undoped catalyst surfaces.

The higher or lower hydrophilicity of the catalyst is directly affected by the $\mathrm{N}$ content. Then, when representing the 4-NP conversion obtained by CWPO, TOC removal, $\mathrm{H}_{2} \mathrm{O}_{2}$ conversion or $\eta_{\mathrm{H}_{2} \mathrm{O}_{2}}$ efficiency versus the catalyst contact angle (Figure 9), the higher $\mathrm{H}_{2} \mathrm{O}_{2}$ decomposition obtained on the highly hydrophilic surfaces of the completely $\mathrm{N}$-doped CNTs is evidenced, but the 4-NP and TOC conversions are lower due to 
the poor efficiency of $\mathrm{H}_{2} \mathrm{O}_{2}$ decomposition, which forms non-reactive species.

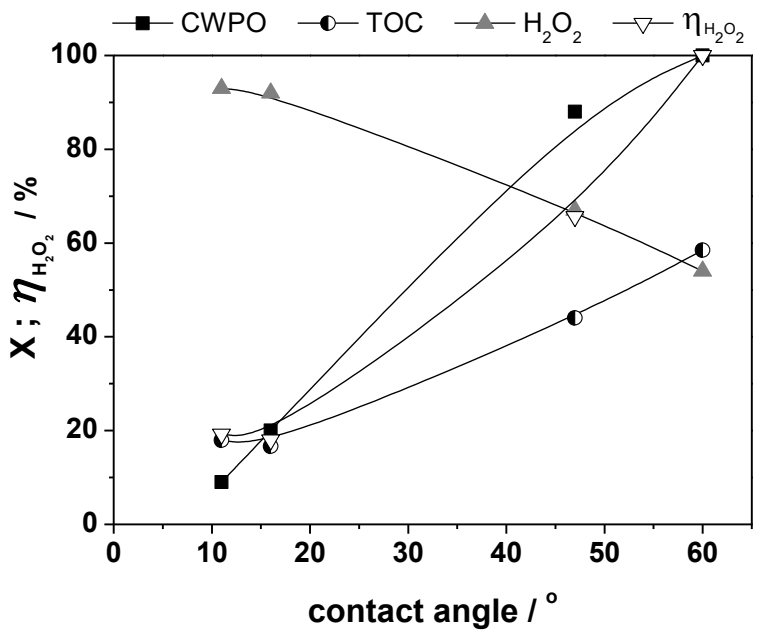

Figure 9. Conversion of 4-NP, TOC removal, $\mathrm{H}_{2} \mathrm{O}_{2}$ decomposition and $\eta_{\mathrm{H}_{2} \mathrm{O}}$ (in \%) obtained for the CWPO experiments after $24 \mathrm{~h}$ as function of the catalyst contact angle $\left({ }^{\circ}\right)$.

\section{Catalyst stability and reusability}

An essential requirement for the industrial application of catalysts is their stability. In order to assess the stability and reusability properties, three consecutive CWPO runs were carried out with the undoped E30 sample - the catalyst showing the best performance. As mentioned in the experimental section, the catalyst was recovered, washed with distilled water, and dried after each run, prior to its re-use in a new CWPO experiment. Figure 10 shows the time evolution of the 4-NP concentration during $24 \mathrm{~h}$ of reaction for the three consecutive CWPO cycles. Around $100 \%$ of the initial pollutant was removed in the first and second cycles after $24 \mathrm{~h}$ of reaction. In the third run, however, the 4-NP conversion decreases, and ca. $30 \mathrm{~h}$ were needed to achieve total pollutant removal (results not shown). Due to the highly oxiddizing reaction environment, the surface chemistry of E30 may change during the CWPO, turning it into a more hydrophilic structure, hindering its use in the consecutive reactions. Additional studies are needed to understand the catalyst performance and identify the reasons for this behavior. Nevertheless, TEM images of the catalysts after CWPO are shown in Figure S6 and their comparison with the catalysts before CWPO (Figure S1) reveal no particular changes in the morphology of the materials during reaction.

Taking into consideration the potential of amphiphilic CNTs in CWPO, the mechanisms involved in the deactivation of these materials are currently under study for further process improvement, as well as its possible optimization by intensification of the operating conditions and the production of more resistant materials against possible chemical alterations during the CWPO process.

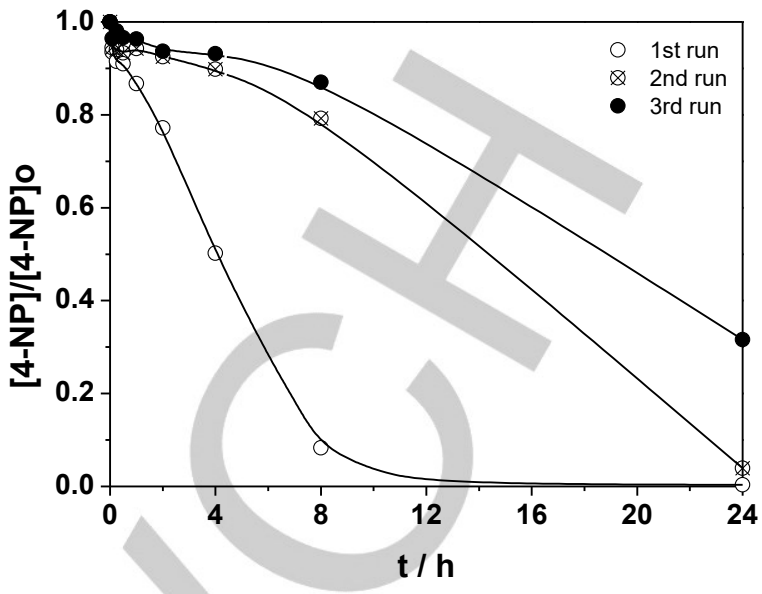

Figure 10. Concentration (normalized by the initial value) evolution with time (h) for 4-NP during three consecutive CWPO experiments using E30.

\section{Conclusions}

Nitrogen doping of magnetic CNTs played a very important role in the CWPO performance of 4-NP. Specifically, it affects the mechanism of $\mathrm{H}_{2} \mathrm{O}_{2}$ decomposition. The controllable $\mathrm{H}_{2} \mathrm{O}_{2}$ decomposition over hydrophobic undoped surfaces favors the formation of reactive $\mathrm{HO}^{*}$. On the other hand, the hydrophilic $\mathrm{N}$-doped surfaces promote the total $\mathrm{H}_{2} \mathrm{O}_{2}$ decomposition into non-reactive species $\left(\mathrm{H}_{2} \mathrm{O}\right.$ and $\left.\mathrm{O}_{2}\right)$. The competition between $\mathrm{H}_{2} \mathrm{O}_{2}$ and 4-NP for the catalyst surface in amphiphilic CNTs makes them promising catalysts for CWPO, since their combined hydrophilic N-doped sections (with high affinity for polar molecules) with undoped sections (ensuring a controllable and effective $\mathrm{H}_{2} \mathrm{O}_{2}$ decomposition) allow them to be explored in wastewater treatment.

\section{Experimental Section}

\section{Chemicals}

The main reactants involved in the process under study, 4-NP (98 wt. \%) and $\mathrm{H}_{2} \mathrm{O}_{2}(30 \%$, w/v), were purchased from Acros Organics and Fluka respectively. Working standard solutions of formic acid (98 wt.\%; Panreac), acetic acid (glacial acetic acid, 99.8 wt.\%; Fisher Chemical), oxalic acid, malonic acid, maleic acid, malic acid, hydroquinone, phenol (all 99 wt.\%; Sigma-Aldrich), 1,4-benzoquinone (99.5 wt.\%; Fluka), catechol (98 wt.\%; Fluka) and 4-nitrocatechol (98 wt.\%; Fluka) were prepared and used for calibration in high-performance liquid chromatography (HPLC). Methanol (HPLC grade, 99.99 wt.\%; Fisher Chemical), glacial acetic acid (HPLC grade, 99.99 wt.\%; Fisher Chemical), acetonitrile (HPLC grade, 99.99 wt.\%; Fisher Chemical) and sulphuric acid $\left(\mathrm{H}_{2} \mathrm{SO}_{4}, 96-98\right.$ wt.\%; Riedel-de-Haën) were used to prepare the mobile phases required for HPLC. The reactants used for the determination of Fe were L-ascorbic acid (99 wt.\%; Fisher Chemical), o-phenanthroline (99 wt.\%; Panreac), glacial acetic acid (HPLC grade, 99.99 wt.\%; Fisher Chemical), ammonium acetate (98 wt.\%; Pronalab) and iron (II) chloride tetrahydrate (99 wt.\%; Sigma-Aldrich). Other reactants used were sodium hydroxide $(\mathrm{NaOH}, 98$ wt.\%; Panreac), 
hydrochloric acid $\left(\mathrm{HCl}, 37 \mathrm{wt} . \%\right.$; Sigma-Aldrich), potassium nitrate $\left(\mathrm{KNO}_{3}\right.$ 99 wt.\%; Sigma-Aldrich), titanium (IV) oxysulphate (15 wt.\% in dilute sulphuric acid, 99.99\%; Sigma-Aldrich) and sodium sulphite $\left(\mathrm{Na}_{2} \mathrm{SO}_{3}\right.$ 98 wt.\%; Sigma-Aldrich). All chemicals were used as received without further purification. Distilled water was used throughout the work except for mobile phase preparation, where ultrapure water was employed.

\section{Synthesis of carbon nanotubes}

The CNTs were synthesized by a catalytic CVD process in a fluidized bed reactor, as described elsewhere ${ }^{[3]}$, using ethylene as carbon source and acetonitrile/ $\mathrm{N}_{2}$ as carbon/nitrogen source, at $650{ }^{\circ} \mathrm{C}$. The synthesis was conducted in the presence of a $\mathrm{Fe} / \gamma-\mathrm{Al}_{2} \mathrm{O}_{3}(20 \mathrm{wt} . \% \mathrm{Fe})$ catalyst prepared by impregnation and reduced in situ at $650^{\circ} \mathrm{C}$ for $30 \mathrm{~min}$. Four samples were produced by feeding to the fluidized bed reactor: (i) ethylene alone for $30 \mathrm{~min}$ (sample E30); (ii) ethylene for $10 \mathrm{~min}$ followed by acetonitrile/ $\mathrm{N}_{2}$ for $20 \mathrm{~min}$ (sample E10A20); (iii) ethylene for $3 \mathrm{~min}$, followed by acetonitrile/ $\mathrm{N}_{2}$ for $27 \mathrm{~min}$ (sample E3A27); and (iv) acetonitrile/ $\mathrm{N}_{2}$ alone for $30 \mathrm{~min}$ (sample A30). Finally, the synthesized CNTs were purified under reflux at $140^{\circ} \mathrm{C}$, with an aqueous solution of $\mathrm{H}_{2} \mathrm{SO}_{4}(50$ vol.\%) for $3 \mathrm{~h}$ to facilitate the total dissolution of the alumina and exposed Fe particles.

\section{Characterization of the carbon nanotubes}

$\mathrm{N}_{2}$ adsorption-desorption isotherms $\left(-196{ }^{\circ} \mathrm{C}\right)$ were obtained to characterize the textural properties of the materials (Quantachrome autosorb-iQ2). The samples were previously outgassed for $12 \mathrm{~h}$ at $120^{\circ} \mathrm{C}$. The $\mathrm{S}_{\mathrm{BET}}$ was calculated by the BET equation ${ }^{[49]}$, while the $\mathrm{V}_{\text {meso }}$ and $V_{\text {pore }}$ volumes were estimated using the BJH method ${ }^{[50]}$. The surface chemical composition of the CNTs was analyzed by XPS (Kratos AXIS Ultra HSA spectrometer), using $\mathrm{Mg}-\mathrm{K} \alpha$ radiation $(1486.7 \mathrm{eV})$. The elements present and their corresponding concentrations were determined by recording general XPS spectra, scanning up to a binding energy (BE) of $1300 \mathrm{eV}$. The $\mathrm{C}$ 1s peak $(284.9 \mathrm{eV})$ was taken as an internal standard to correct the shift in $\mathrm{BE}$ caused by sample charging. The $B E$ of the $C 1 s, N 1 s, O 1 s$ and $F e 2 p_{3 / 2}$ core levels and the full width at half maximum values were used to assess the chemical state of these elements on the catalyst surface, according to NIST database. Potentiometric titration (Metrohm 670 automatic titrator) was used to estimate the concentration of acidic active sites at the catalysts surface. $50 \mathrm{mg}$ of CNT dispersed in $25 \mathrm{~mL}$ of aqueous $\mathrm{HCl}\left(0.0070 \mathrm{~mol} \mathrm{~L}^{-1}\right)$ and $\mathrm{KNO}_{3}\left(0.04 \mathrm{~mol} \mathrm{~L}^{-1}\right)$ solutions were placed directly into the electrochemical cell and titrated with a $\mathrm{CO}_{2}$-free $\mathrm{NaOH}$ solution $\left(0.0524 \mathrm{~mol} \mathrm{~L}^{-1}\right)$. The experimental data were treated according to the literature ${ }^{[51,52]}$. TGA analysis were performed using an Elmer Diamond $T G / D T A$ thermo balance, heating the sample powders at $10{ }^{\circ} \mathrm{C} \mathrm{min}^{-1}$ up to $1000{ }^{\circ} \mathrm{C}$ in air atmosphere $\left(50 \mathrm{~cm}^{3} \mathrm{~min}^{-1}\right)$. The hydrophobicity/hydrophilicity of the CNTs (in the form of buckypapers) was determined by water contact angle measurements using an Attension optical tensiometer (model Theta) that allowed image acquisition and data analysis. The measurements with water were performed on dry buckypapers at room temperature using the sessile drop method [38]. Each contact angle was measured at least in five different locations on the buckypapers in order to determine the average value. TEM images were obtained using a TEM-FEI microscope (TecnaiG2-20-FEI 2006) operating at $200 \mathrm{kV}$. The samples magnetism was verified qualitatively using magnets (Figure S7)

CWPO, adsorption, and $\mathrm{H}_{2} \mathrm{O}_{2}$ decomposition experiments
The CWPO runs were conducted in a batch reaction system consisting of a $250 \mathrm{~mL}$ magnetically stirred $(600 \mathrm{rpm})$ glass reactor, equipped with a reflux condenser and a sample collection port, immersed in an oil bath with temperature control. In a typical experiment, the reactor was loaded with $50 \mathrm{~mL}$ of the 4-NP aqueous solution $\left(5 \mathrm{~g} \mathrm{~L}^{-1}\right)$ and heated up to $50{ }^{\circ} \mathrm{C}$. After temperature stabilization, $\mathrm{pH}$ was adjusted to 3 using $\mathrm{H}_{2} \mathrm{SO}_{4}$ and $\mathrm{NaOH}$ solutions, and a calculated volume of $\mathrm{H}_{2} \mathrm{O}_{2}$ was incorporated to the system in order to reach the stoichiometric concentration needed to mineralize completely 4-NP. The reaction started with the addition of $0.125 \mathrm{~g}$ of catalyst corresponding to a catalyst load of $2.5 \mathrm{~g} \mathrm{~L}^{-1}$. During the experiment, samples of the resulting effluent were collected at different reaction times (typically at $0,5,15,30,60,120,240,480$ and $1440 \mathrm{~min}$ ) and prepared for analysis, as described in the 'Analytical methods' section. After $24 \mathrm{~h}$ of reaction, the catalyst was separated by filtration (20 $\mu \mathrm{m}$, Prat Dumas), washed with distilled water and dried at 60 ${ }^{\circ} \mathrm{C}$. A blank experiment, i.e. without catalyst, was carried out to assess possible non-catalytic oxidation reactions promoted by $\mathrm{H}_{2} \mathrm{O}_{2}$. On the other hand, the adsorption capacity of the different synthesized CNTs was evaluated by means of pure adsorption experiments, in which the operating conditions used in the CWPO runs were reproduced, but a volume of distilled water was incorporated to the system in substitution of $\mathrm{H}_{2} \mathrm{O}_{2}$. Finally, to assess the activity of the catalysts to decompose $\mathrm{H}_{2} \mathrm{O}_{2}$ avoiding pollutant competition, a set of experiments was carried out by introducing $50 \mathrm{~mL}$ of distilled water in the reactor instead of the 4-NP aqueous solution. The experiments were performed in triplicate, the standard deviation being less than $5 \%$ in all cases.

\section{Analytical methods}

4-NP and the aromatic intermediates derived from its oxidation were identified and quantified by HPLC, adapting the procedure described elsewhere [53], using a Jasco system equipped with an UV-VIS detector (UV-2075 Plus) and a quaternary gradient pump (PU-2089 Plus) for solvent delivery $\left(1 \mathrm{~mL} \mathrm{~min}^{-1}\right)$. The stationary phase consisted in a Kromasil 100-5-C18 column $(15 \mathrm{~cm} \times 4.6 \mathrm{~mm} ; 5 \mu \mathrm{m}$ particle size) working at room temperature. As explained above, small aliquots were periodically withdrawn from the reactor. An excess of $\mathrm{Na}_{2} \mathrm{SO}_{3}$ was immediately added to consume the residual $\mathrm{H}_{2} \mathrm{O}_{2}$ and the catalyst was removed by filtration to stop the reaction ${ }^{[33,36,54]}$. The mobile phase consisted of an isocratic method of an $A: B(40: 60)$ mixture of $3 \%$ acetic acid and $1 \%$ acetonitrile in methanol $(A)$ and $3 \%$ acetic acid in ultrapure water (B). The absorbance wavelength was adjusted to $318 \mathrm{~nm}$ for the determination of 4-NP, and to $277 \mathrm{~nm}$ for the aromatic intermediates. The concentration of carboxylic acids was monitored by a Jasco HPLC system fitted with an YMC - Triart C18 column $(25 \mathrm{~cm} \times 4.6 \mathrm{~mm} ; 5 \mu \mathrm{m}$ particle size), adapting the procedures reported elsewhere [55,56]. The mobile phase consisted of an isocratic method of an A:B (95:5) mixture of $1 \%$ sulphuric acid in ultrapure water $(A)$ and acetonitrile $(B)$, delivered to the system at $0.6 \mathrm{~mL} \mathrm{~min}{ }^{-1}$. The UV/VIS detector was set to $210 \mathrm{~nm}$. The TOC content and the concentration of nitrate ions were determined using a Shimadzu TOC-5000A analyzer and a Metrohm 881 Compact lon Chromatograph equipped with a Metrosep A Supp 7-250 column, respectively. The concentrations of $\mathrm{H}_{2} \mathrm{O}_{2}$ and $\mathrm{Fe}$ in solution were determined by colorimetric methods with a UVIVIS spectrophotometer ( $T 70$ spectrometer, PG Instruments Ltd.). For the determination of $\mathrm{H}_{2} \mathrm{O}_{2}$, a filtered sample was acidified with a $\mathrm{H}_{2} \mathrm{SO}_{4} 0.5 \mathrm{M}$ solution. $0.1 \mathrm{~mL}$ of titanium oxysulfate was added, and the absorbance was measured at $405 \mathrm{~nm}{ }^{[57]}$. On the other hand, the concentration of $\mathrm{Fe}$ species leached at the end of the experiments was determined by the o-phenanthroline method, according to ISO $6332{ }^{[58]}$, using ascorbic acid as reducing agent, and measuring the absorbance at $510 \mathrm{~nm}$. 


\section{Acknowledgements}

This work was co-financed by FCT and FEDER under Programme PT2020 (Project UID/EQU/50020/2013) and Programme COMPETE (FCOMP-01-0124-FEDER-020706), and by QREN, ON2, FCT and FEDER (Project NORTE-07-0124FEDER-000015). M. Martin-Martinez (Postdoc grant SFRH/BPD/108510/2015), R.S. Ribeiro (Ph.D. grant SFRH/BD/94177/2013, co-financed by FCT and the European Social Fund through $\mathrm{POPH}$ and QREN), S. Morales-Torres (Postdoc grant SFRH/BPD/108981/2015) and A.M.T. Silva (FCT Investigator 2013 Programme IF/01501/2013) acknowledge financial support from the FCT.

Keywords: amphiphilic catalysts $\cdot$ catalytic wet peroxide oxidation • doping $\bullet$ hydrophilicity/hydrophobicity $\bullet$ nanotubes

[1] P. Zhang, H. Zhu, S. Dai, ChemCatChem 2015, 7, 2788-2805.

[2] P. Serp, M. Corrias, P. Kalck, Appl. Catal., A 2003, 253, 337-358.

[3] A. D. Purceno, B. F. Machado, A. P. C. Teixeira, T. V. Medeiros, A Benyounes, J. Beausoleil, H. C. Menezes, Z. L. Cardeal, R. M. Lago, P Serp, Nanoscale 2015, 7, 294-300.

[4] M. Pera-Titus, L. Leclercq, J. Clacens, F. De Campo, V. Nardello-Rataj, Angew. Chem., Int. Ed. 2015, 54, 2006-2021.

[5] Y. Yang, W. Zhang, X. Ma, H. Zhao, X. Zhang, ChemCatChem 2015, 7 3454-3459.

[6] A. Benyounes, S. Louisia, R. Axet, Z. Mahfoud, M. Kacimi, P. Serp, Catal. Today 2015, 249, 137-144.

[7] K. V. Voitko, R. L. D. Whitby, V. M. Gun'ko, O. M. Bakalinska, M. T. Kartel, K. Laszlo, A. B. Cundy, S. V. Mikhalovsky, J. Colloid Interface Sci. 2011 361, 129-136.

[8] K. Voitko, A. Tóth, E. Demianenko, G. Dobos, B. Berke, O. Bakalinska, A Grebenyuk, E. Tombácz, V. Kuts, Y. Tarasenko, M. Kartel, K. László, J. Colloid Interface Sci. 2015, 437, 283-290.

[9] R. Andreozzi, V. Caprio, A. Insola, R. Marotta, Catal. Today 1999, 53, 51 59.

[10] G. Pliego, J. A. Zazo, P. Garcia-Munoz, M. Munoz, J. A. Casas, J. J Rodriguez, Crit. Rev. Environ. Sci. Technol. 2015, 45, 2611-2692.

[11] S. Azabou, W. Najjar, M. Bouaziz, A. Ghorbel, S. Sayadi, J. Hazard. Mater. 2010, 183, 62-69.

[12] S. Navalon, A. Dhakshinamoorthy, M. Alvaro, H. Garcia, ChemSusChem 2011, 4, 1712-1730.

[13] C. W. Jones, Applications of hydrogen peroxide and derivatives, Royal Society of Chemistry, 1999

[14] R. S. Ribeiro, A. M. T. Silva, J. L. Figueiredo, J. L. Faria, H. T. Gomes, Carbon 2013, 62, 97-108.

[15] G. V. Buxton, C. L. Greenstock, W. P. Helman, A. B. Ross, J. Phys. Chem Ref. Data 1988, 17, 513-886.

[16] W. H. Koppenol, J. Butler, J. W. v. Leeuwen, Photochem. Photobiol. 1978 28, 655-658

[17] S. Ghafoori, M. Mehrvar, P. K. Chan, Ind. Eng. Chem. Res. 2012, 51 , 14980-14993.

[18] T. Schaefer, J. Schindelka, D. Hoffmann, H. Herrmann, J. Phys. Chem. A 2012, 116, 6317-6326.

[19] A. Rey, A. Bahamonde, J. A. Casas, J. J. Rodriguez, Water Sci. Technol. 2010, 61, 2769-2778.

[20] A. Aguinaco, J. P. Pocostales, J. Garcia-Araya, F. J. Beltran, J. Chem. Technol. Biotechnol. 2011, 86, 595-600.

[21] B. H. J. Bielski, D. E. Cabelli, R. L. Arudi, A. B. Ross, J. Phys. Chem. Ref Data 1985, 14, 1041-100.

[22] A. J. Elliot, G. V. Buxton, J. Chem. Soc., Faraday Trans. 1992, 88, 246570.
[23] E. V. Rokhina, J. Virkutyte, Crit. Rev. Environ. Sci. Technol. 2011, 41 125-167.

[24] G. Calleja, J. A. Melero, F. Martinez, R. Molina, Water Res. 2005, 39 , $1741-1750$

[25] A. Rey, M. Faraldos, J. A. Casas, J. A. Zazo, A. Bahamonde, J. J. Rodriguez, Appl. Catal., B 2009, 86, 69-77.

[26] A. Onda, Y. Suzuki, S. Takemasa, K. Kajiyoshi, K. Yanagisawa, J. Mater Sci. 2008, 43, 4230-4235.

[27] F. Martinez, J. A. Melero, J. A. Botas, M. I. Pariente, R. Molina, Ind. Eng Chem. Res. 2007, 46, 4396-4405.

[28] L. Liu, Y. Zhu, M. Su, Z. Yuan, ChemCatChem 2015, 7, 2765-2787.

[29] R. S. Ribeiro, A. M. T. Silva, M. T. Pinho, J. L. Figueiredo, J. L. Faria, H. T. Gomes, Catal. Today 2015, 240, 61-66

[30] P. Serp, J. L. Figueiredo, Editors., Carbon Materials for Catalysis, John Wiley \& Sons, Inc 2009.

[31] C. M. Domínguez, P. Ocón, A. Quintanilla, J. A. Casas, J. J. Rodriguez, Appl. Catal., B 2013, 140-141, 663-670.

[32] M. T. Pinho, H. T. Gomes, R. S. Ribeiro, J. L. Faria, A. M. T. Silva, Appl Catal., B 2015, 165, 706-714.

[33] R. S. Ribeiro, A. M. T. Silva, J. L. Figueiredo, J. L. Faria, H. T. Gomes, Appl. Catal., B 2013, 140-141, 356-362.

[34] W. Liu, J. Qian, K. Wang, H. Xu, D. Jiang, Q. Liu, X. Yang, H. Li, J. Inorg. Organomet. Polym. Mater. 2013, 23, 907-916

[35] F. Martínez, M. I. Pariente, J. Á. Botas, J. A. Melero, A. Rubalcaba, Chem. Technol. Biotechnol. 2012, 87, 880-886.

[36] F. Duarte, F. J. Maldonado-Hódar, L. M. Madeira, Appl. Catal., B 2011 $103,109-115$

[37] H. C. Menezes, S. M. R. de Barcelos, D. F. D. Macedo, A. D. Purceno, B. F. Machado, A. P. C. Teixeira, R. M. Lago, P. Serp, Z. L. Cardeal, Anal. Chim. Acta 2015, 873, 51-56.

[38] S. Morales-Torres, T. L. S. Silva, L. Pastrana-Martinez, A. T. S. C. Brandao, J. L. Figueiredo, A. M. T. Silva, Phys. Chem. Chem. Phys. 2014, 16, 12237-12250.

[39] G. E. Romanos, V. Likodimos, R. R. N. Marques, T. A. Steriotis, S. K Papageorgiou, J. L. Faria, J. L. Figueiredo, A. M. T. Silva, P. Falaras, J Phys. Chem. C 2011, 115, 8534-8546.

[40] M. Soria-Sánchez, E. Castillejos-López, A. Maroto-Valiente, M. F. R Pereira, J. J. M. Órfão, A. Guerrero-Ruiz, Appl. Catal., B 2012, 121 122, 182-189.

[41] Q. Yang, P. Hou, S. Bai, M. Wang, H. Cheng, Chem. Phys. Letters 2001 345, 18-24

[42] A. A. Koós, M. Dowling, K. Jurkschat, A. Crossley, N. Grobert, Carbon 2009, 47, 30-37.

[43] D. Bom, R. Andrews, D. Jacques, J. Anthony, B. Chen, M. S. Meier, J. P. Selegue, Nano Lett. 2002, 2, 615-619.

[44] V. V. Strelko, V. S. Kuts, P. A. Thrower, Carbon 2000, 38, 1499-1503

[45] R. S. Ribeiro, A. M. T. Silva, L. Pastrana-Martinez, J. L. Figueiredo, J. L. Faria, H. T. Gomes, Catal. Today 2015, 249, 204-212.

[46] A. Rey, J. A. Zazo, J. A. Casas, A. Bahamonde, J. J. Rodriguez, Appl. Catal., A 2011, 402, 146-155

[47] C. M. Domínguez, A. Quintanilla, P. Ocón, J. A. Casas, J. J. Rodriguez, Carbon 2013, 60, 76-83

[48] M. A. Oturan, J. Peiroten, P. Chartrin, A. J. Acher, Environ. Sci. Technol. 2000, 34, 3474-3479.

[49] S. Brunauer, P. H. Emmett, E. Teller, J. Am. Chem. Soc. 1938, 60, 309 319.

[50] E. P. Barrett, L. G. Joyner, P. P. Halenda, J. Am. Chem. Soc. 1951, 73 , 373-80.

[51] J. P. de Mesquita, P. B. Martelli, H. d. F. Gorgulho, J. Braz. Chem. Soc. 2006, 17, 1133-1143.

[52] H. F. Gorgulho, J. P. Mesquita, F. Gonçalves, M. F. R. Pereira, J. L. Figueiredo, Carbon 2008, 46, 1544-1555.

[53] Â. C. Apolinário, A. M. T. Silva, B. F. Machado, H. T. Gomes, P. P. Araújo, J. L. Figueiredo, J. L. Faria, Appl. Catal., B 2008, 84, 75-86. 
[54] J. H. Ramirez, C. A. Costa, L. M. Madeira, G. Mata, M. A. Vicente, M. L. Rojas-Cervantes, A. J. López-Peinado, R. M. Martín-Aranda, Appl. Catal., B 2007, 71, 44-56.

[55] R. P. Rocha, J. P. S. Sousa, A. M. T. Silva, M. F. R. Pereira, J. L. Figueiredo, Appl. Catal., B 2011, 104, 330-336.

[56] L. Yang, L. Liu, B. A. Olsen, M. A. Nussbaum, J. Pharm. Biomed. Anal. 2000, 22, 487-493.
[57] W. C. Ketchie, Y. Fang, M. S. Wong, M. Murayama, R. J. Davis, J. Catal. 2007, 250, 94-101.

[58] ISO 6332:1988, 1988. 


\section{Entry for the Table of Contents}

\section{FULL PAPER}

$\mathrm{N}$-groups enhance the catalyst activity for $\mathrm{H}_{2} \mathrm{O}_{2}$ decomposition into $\mathrm{HO}^{\circ}$ radicals. But watch out. Completely $\mathrm{N}$ doped carbon nanotubes, highly hydrophilic, promote their recombination into non-reactive $\mathrm{O}_{2}$ and $\mathrm{H}_{2} \mathrm{O}$ species. Less ambitious selectively $\mathrm{N}$-doped nanotubes take advantage of a rapid $\mathrm{H}_{2} \mathrm{O}_{2}$ decomposition achieving high 4-NP removal.

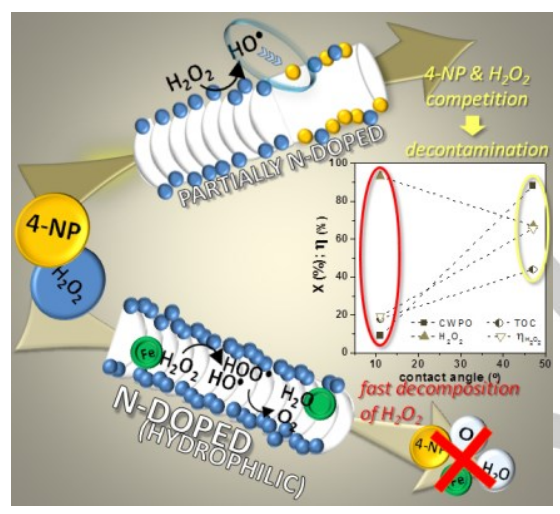

Maria Martin-Martinez, Rui S. Ribeiro, Bruno F. Machado, Philippe Serp, Sergio Morales-Torres, Adrián M.T. Silva, José L. Figueiredo, Joaquim L. Faria, and Helder T. Gomes*

Page No. - Page No.

Less is more 


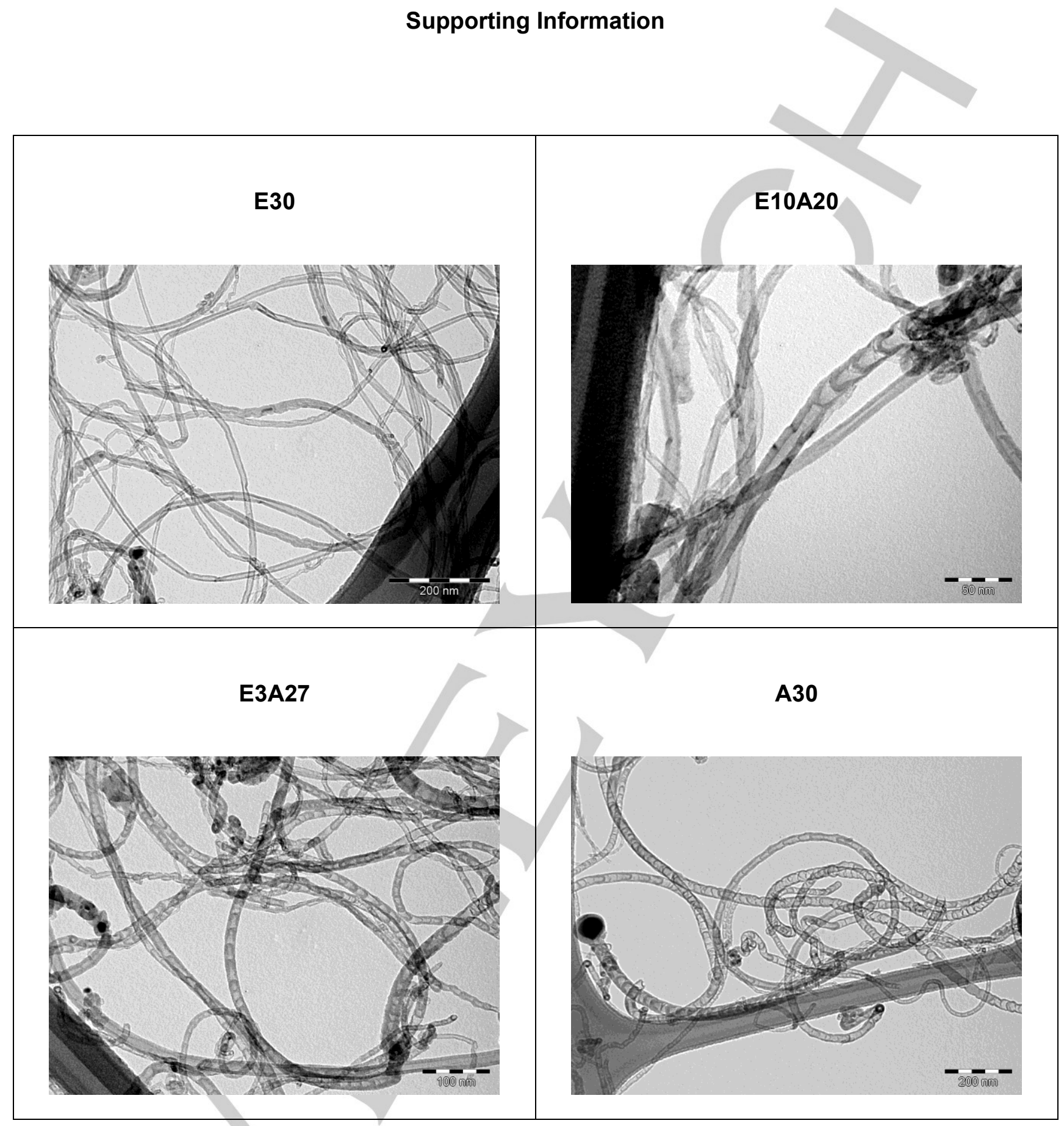

Figure S1. TEM micrographs of the four CNTs samples. 

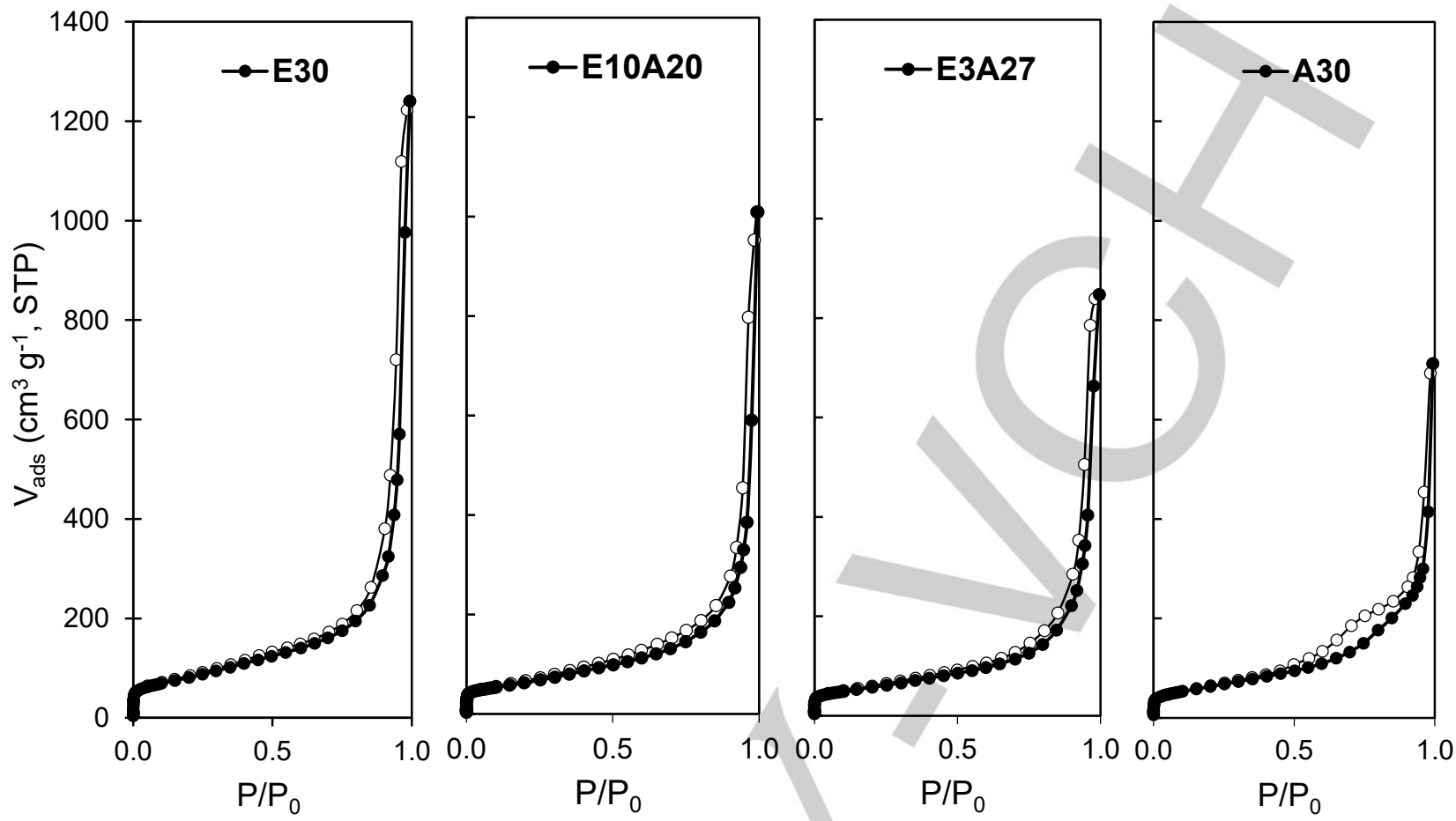

Figure S2. $\mathrm{N}_{2}$ adsorption-desorption isotherms of the CNTs obtained at $-196^{\circ} \mathrm{C}$. 

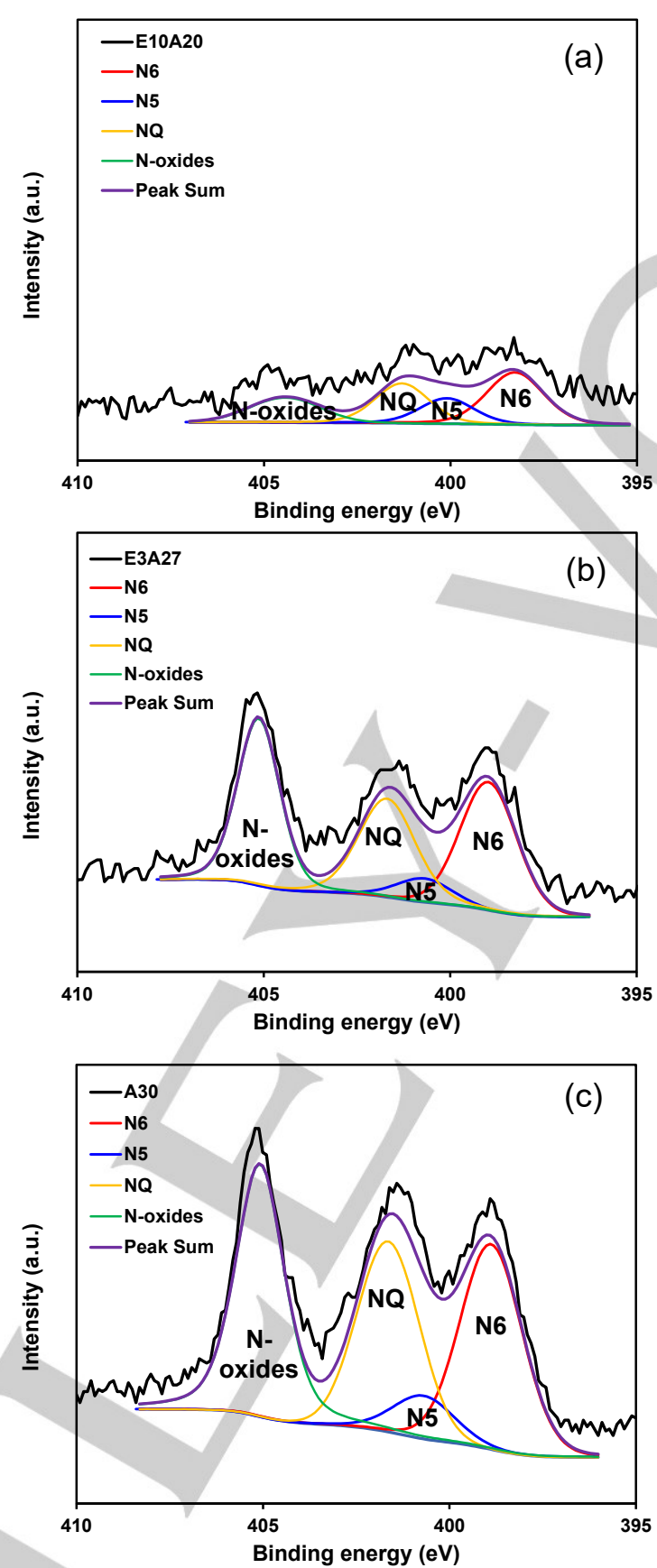

Figure S3. XPS spectra and deconvolution of the N1s region of E10A20 (a), E3A27 (b) and A30 (c): pyridinic nitrogen (N6, red), pyrrolic nitrogen (N5, blue), quaternary nitrogen ( $\mathrm{NQ}$, yellow) and nitrogen oxides ( $\mathrm{N}$-oxides, green). 

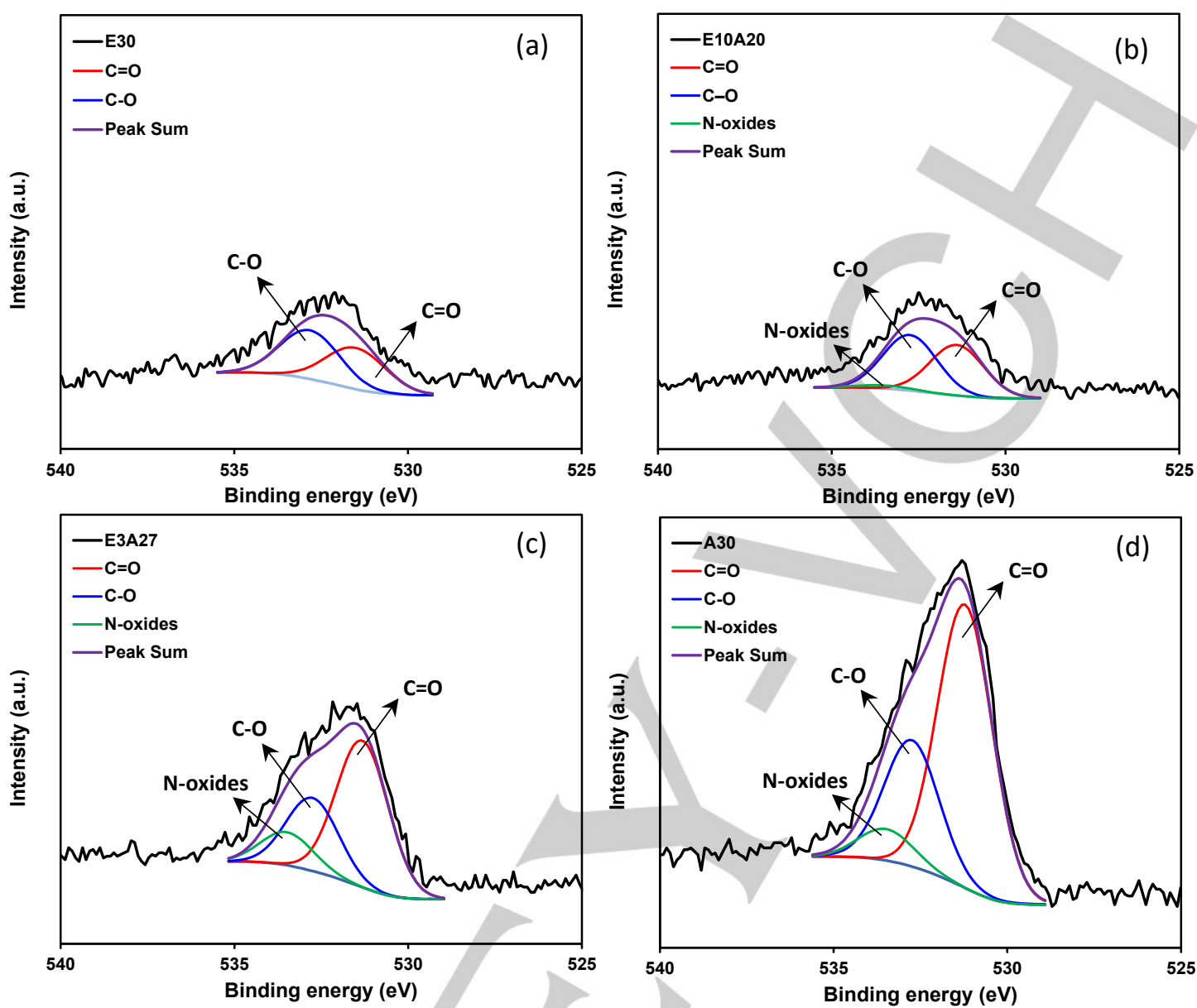

Figure S4. XPS spectra and deconvolution of the O1s region of E30 (a), E10A20 (b), E3A27 (c) and A30 (d). 


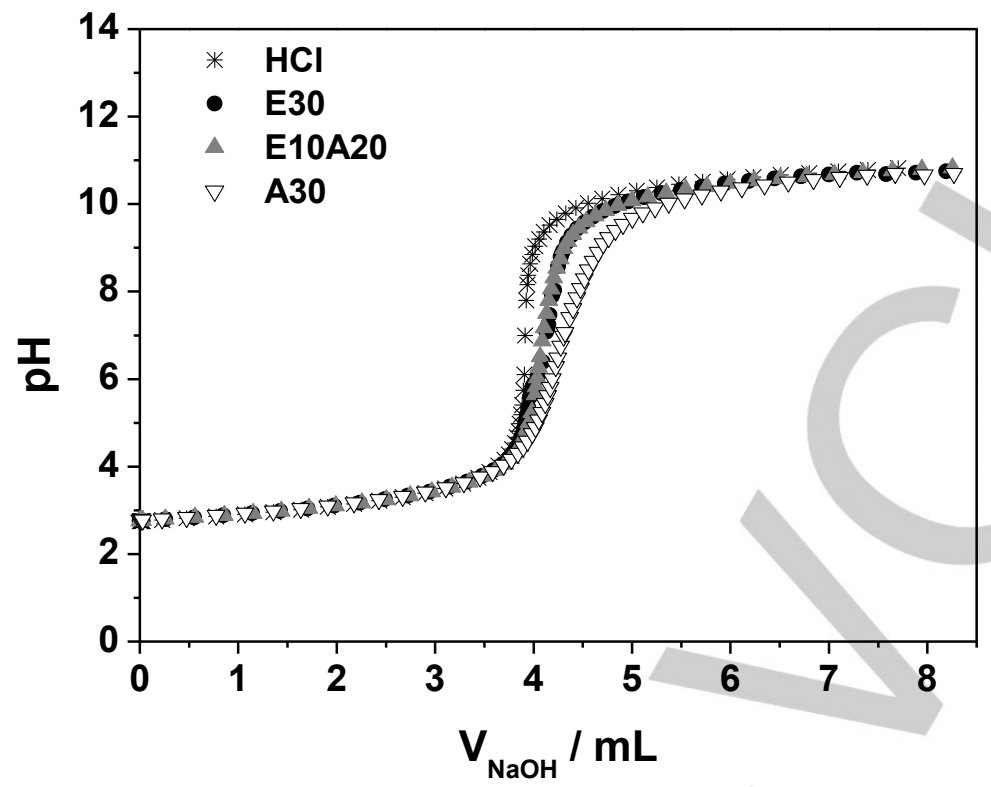

Figure S5. Potentiometric titration curves of the CNTs dispersed in $\mathrm{HCl}\left(0.0070 \mathrm{~mol} \mathrm{~L}^{-1}\right)+\mathrm{KNO}_{3}\left(0.04 \mathrm{~mol} \mathrm{~L}^{-1}\right)$ aqueous solutions (represented as $\mathrm{HCl}$ for reference purposes). 


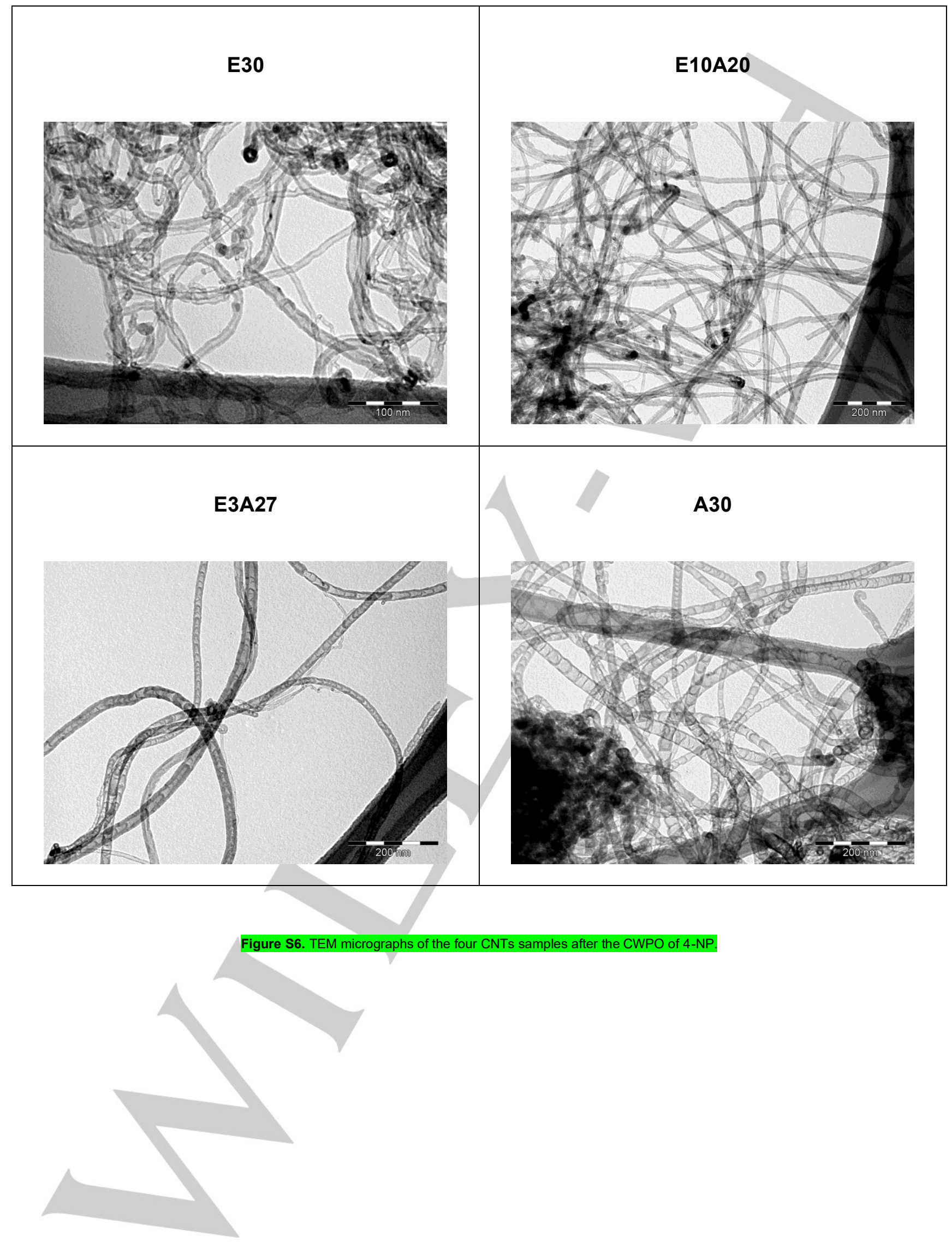



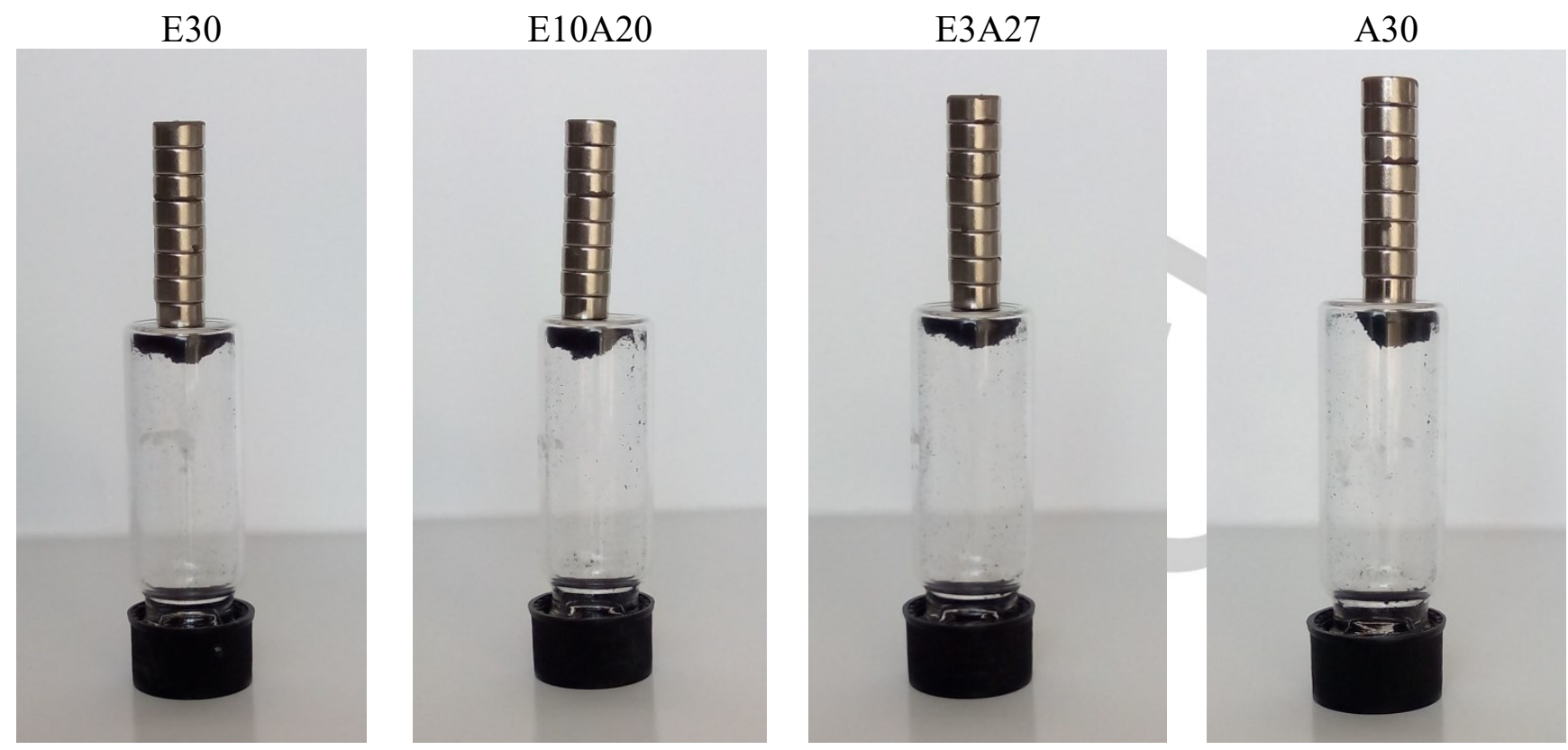

Figure S7. Magnetism of the four CNTs samples.

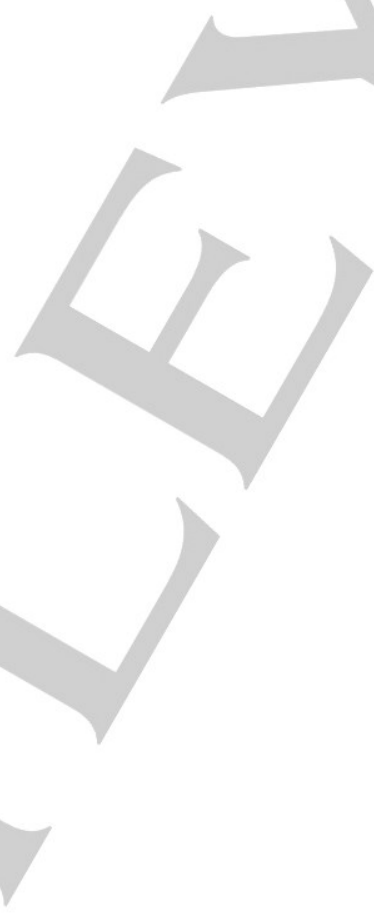

